\title{
福建平潭岛海域底栖贝类物种多样性及其地理分布
}

\author{
胡亮 (1D*
}

中山大学地理科学与规划学院, 广州 510275

摘要: 海洋底栖贝类是海洋底栖无脊椎动物的重要代表。福建平潭岛地处台湾海峡西岸北部, 是中国大陆距台湾岛最近之处, 其海域内的底栖贝类区系对了解台湾海峡及其附近海域的生态环境和底栖生物地理格局具有重要意义。本文基于对 2015-2018年间中山大学国土资源与环境系在平潭岛海域采集的3,346号底栖贝类标本的鉴定, 结合已发表文献整理出了平潭 岛海域底栖贝类名录, 并梳理了各物种在中国近海的地理分布类型。结果显示, 本研究所采标本分属58科122属161种，其中 47 种为平潭岛海域新记录。结合历史文献记录, 平潭岛海域共有底栖贝类 98 科244属395种。其中 $93.7 \%$ 的种类在南海亦有分 布, $82.0 \%$ 的种类在东海有分布, $31.1 \%$ 的种类在黄渤海有分布, $42.3 \%$ 的种类在台湾岛东部海域有分布。南海-东海分布型种类 占区系总种数的 $49.9 \%$; 其次为南海-黄渤海分布型(27.6\%)和南海-台湾海峡分布型 $(16.2 \%)$ 。分布限于台湾海峡及其以北的种 类仅占总种数的 $6.3 \%$ 。研究结果表明, 平潭岛海域底栖贝类区系具典型的亚热带性质, 暖水性种类和广温性种类占主要优势, 与南海北部和东海大陆沿岸地区的关系密切, 与台湾岛周边海域的联系相对较弱。

关键词：腹足纲; 双壳纲; 软体动物; 物种多样性; 台湾海峡

胡亮 (2021) 福建平潭岛海域底栖贝类物种多样性及其地理分布. 生物多样性, 29, 1403-1410. doi: 10.17520/biods.2021114.

Hu L (2021) Species diversity and geographical distribution of marine, benthic, shell-bearing mollusks on the coast and adjacent area of Pingtan Island, Fujian Province. Biodiversity Science, 29, 1403-1410. doi: 10.17520/biods.2021114.

\section{Species diversity and geographical distribution of marine, benthic, shell-bearing mollusks on the coast and adjacent area of Pingtan Island, Fujian Province}

Liang $\mathrm{Hu}^{\left({ }^{*}\right.}$

School of Geography and Planning, Sun Yat-sen University, Guangzhou 510275

\begin{abstract}
Aims: Marine, benthic, shell-bearing mollusks are one of the most important groups of marine benthic invertebrates. Pingtan Island is an island in the northwestern part of the Taiwan Strait. The marine, benthic, shelled fauna in this area are important for revealing the ecological environment and biogeographical pattern of the Taiwan Strait and its adjacent waters. Here, we report the species diversity and distribution patterns of shelled-mollusks found in Pingtan Island and its adjacent waters.

Methods: We conducted a checklist of known marine, benthic, shells found near Pingtan Island and its adjacent waters based on previous studies and 3,346 specimens collected by the Department of Physical Geography, Resources and Environment, Sun Yat-sen University from 2015-2018. We then investigated distribution patterns of each listed species in the coast waters of China.

Results: We identified a total of 161 species from 122 genera and 58 families. Of these 161 species, 47 species were new to the study area. In total, 395 species of mollusks belonging to 244 genera and 98 families are reported to inhabit Pingtan Island and its adjacent waters. Of them, 93.7\% of the species are also distributed in the South China Sea, 82.0\% in the East China Sea, 31.1\% in the Yellow and Bohai Seas, and 42.3\% in the waters east of Taiwan Island. The distribution pattern between the South China Sea and the East China Sea accounted for 49.9\% of the total species. The distribution pattern between the South China Sea and the Yellow and Bohai Seas accounted for 27.6\% of the total species. The distrubition pattern between the South China Sea and the Taiwan Strait accounted for $16.2 \%$ of the total
\end{abstract}

收稿日期: 2021-03-26; 接受日期: 2021-06-01

基金项目: 中央高校基本科研业务费专项资金(13lgpy09)和中山大学本科教学质量工程类项目(31911130)

* 通讯作者 Author for correspondence. E-mail: huliang_hy@163.com 
species. Only 6.3\% of the species were confined to be limited to the Taiwan Strait and the region to the north of it. Conclusions: The marine, benthic, shell-bearing mollusks in Pingtan Island have typical subtropical characteristics, among which warm and eurythermic species are dominant. The shelled-mollusks in Pingtan Island has a close relationship with that of the continental shelves of the South China Sea (northern part) and East China Sea. In contrast, the relationship between shelled-mollusks in Pingtan Island and that of the waters around the Taiwan Island is relatively weak.

Key words: Gastropoda; Bivalvia; mollusks; species diversity; Taiwan Strait

海洋底栖贝类是指营底栖生活的具壳海洋软 体动物, 通常包括生活在潮上带、潮间带和海洋环 境中的掘足纲、多板纲、双壳纲和腹足纲的物种 (Higo et al, 1999)。海洋底栖贝类是海洋底栖生物中 无脊椎动物的重要代表, 是反映海洋生态环境和海 洋生物地理格局的基本生态类群之一。中国大陆和 岛屿海岸线漫长, 海洋底栖贝类物种十分丰富, 但 底栖贝类区系本底资料的质量整体上还亟待提升。 一方面, 标本的质量尚不尽如人意。例如, 我国发 现的128种芋螺科种类中, 32种仅有空壳标本, 18种 仅有 1 个标本, 4 种仅有分布记录而无标本(李凤兰和 林民玉, 2016)。另一方面, 物种的地理分布记录还 在逐步完善中。例如, 赖景阳和欧阳盛芝(1996)曾报 道产澎湖列岛的贝类共 686 种, 而据台湾省贝类资 料库(https://shell.sinica.edu.tw), 目前该海域的贝类 记录已达915种。因此, 标本的积累和地理分布数据 的更新对了解和掌握我国海洋底栖贝类物种多样 性和生物地理格局至关重要。台湾海峡是连通东海 和南海动物区系的重要通道, 在海洋生物地理学上 具有重要意义。近年来对该海域底栖贝类的多样性 和生态学研究有了长足的进步, 但对局部海域贝类 区系的研究相对欠缺。

平潭岛又称海坛岛, 位于福建省福州市, 是福 建省第一大岛, 我国第五大岛。该岛地处台湾海峡 西侧北部, 西隔海坛海峡与大陆相望, 东与台湾省 新竹港相距仅68海里, 是中国大陆距台湾岛最近之 处。平潭岛独特的地理位置和丰富的底栖贝类物种, 使其在底栖生物地理学上也有重要的意义。不少种 类在大陆沿海的分布北界即止于平潭, 如强缘凤螺 (Margistrombus robustus) (张素萍, 2016)、亮樱蛤 (Nitidotellina hokkaidoensis) (徐凤山和张均龙, 2018) 和棘赤蛙螺(Bufonaria perelegans) (张素萍和马绣同, 2004)。一些分布区狭窄的种类如摺扇笋螺 (Punctoterebra nitida) 目前在大陆沿海仅平潭岛海 域有记录(钟幼平和杨瑞琼, 1996), 长尖石蛏
(Leiosolenus lepteces)仅见于福建东山和平潭(王祯 瑞, 1997)。自20世纪中叶开始, 国内已有学者和单 位在平潭岛海域采集标本(蔡英亚, 1960, 1966; 张 玺和齐钟彦, 1962; 张胥和黄修明, 1964), 是国内较 早开展贝类区系研究的站点之一。20世纪末, 王方 平和黄一鸣(1993，1994)先后整理了福建沿海的前 鳃类和双壳类区系。经本文作者校对, 其中共有 250 种(腹足纲123种, 双壳纲127种)底栖贝类产平潭岛 海域, 是迄今为止对平潭岛海域底栖贝类种类记录 最丰富的报道。自两文发表的20多年间, 先后有许 多新的分布记录发现, 但多分散于期刊论文(钟幼 平和杨瑞琼, 1996; 张素萍, 2007; 黄雅琴等, 2009)、 专著(徐凤山, 1997; 李荣冠, 2010; 黄宗国和林茂, 2012)或学位论文(李宝泉, 2007; 陈志云, 2012; 张 树乾, 2015)之中, 缺乏系统的整理。

本文基于对2015-2018年间中山大学国土资源 与环境系在平潭岛海域采集的贝类标本的鉴定, 结 合历史文献报道对该区域底栖贝类的物种多样性 及各物种的地理分布进行了整理和汇总, 以期完善 该海域底栖贝类区系基础资料, 为今后该海域底栖 生物多样性与保护以及台湾海峡及邻近海域的底 栖生物地理格局与地理区划提供参考依据。

\section{材料与方法}

平潭岛位于 $25^{\circ} 15^{\prime}-25^{\circ} 45^{\prime} \mathrm{N}, 119^{\circ} 32^{\prime}-120^{\circ} 10^{\prime} \mathrm{E}$, 地处南亚热带北界。本文所指平潭岛海域包括平潭 岛及其附近岛屿的潮上带、潮间带和浅海环境。平 潭岛海域年均海水表层温度 $19.4-20.1^{\circ} \mathrm{C}$, 年均盐度 30.5\%o-31.9\%o (平潭县地方志编纂委员会, 2000)。 2015-2018年期间, 中山大学国土资源与环境系师 生前后6次对平潭岛长江澳、海坛湾、坛南湾、石 牌洋等地的潮上带和潮间带底栖贝类进行了考察, 期间也考察了当地市场上出售的经济贝类, 前后共 采集底栖贝类活体和空壳标本 3,346 号, 贝类活体 经蒸煮处理后保留贝壳, 干制标本存放于中山大学 
胡亮: 福建平潭岛海域底栖贝类物种多样性及其地理分布 1405

地理科学与规划学院生物标本室。

物种鉴定主要参考《中国水生贝类图鉴》(郑小 东等, 2013)、《中国海洋贝类图鉴》(张素萍, 2008)、 《黄渤海软体动物图志》(张素萍等, 2016)、《台湾 现生贝类彩色图鉴》(胡忠恒和陶锡珍, 1995)、《中 国南海经济贝类原色图鉴》(杨文等, 2017)及《中国 动物志》软体动物门相关卷册(王祯瑞, 1997; 庄启 谦, 2001; 董正之, 2002; 张素萍和马绣同, 2004; 徐 凤山, 2012; 李凤兰和林民玉, 2016; 张素萍, 2016; 徐凤山和张均龙, 2018)。结合已鉴定物种及已发表 文献记录, 汇总编制了平潭岛海域底栖贝类名录, 并对文献记录中的异名参考数据库 WoRMS (http://www.marinespecies.org)和GBIF (https://www. gbif.org)进行了校对。根据对现有文献和专著的系 统检索和查阅, 对平潭岛海域每种底栖贝类在黄渤 海、东海、南海、台湾岛东侧海域以及邻近地区(南 澳及南澎列岛、厦门湾、洞头及南鹿列岛、澎湖列 岛、台湾岛东北部)的分布进行了汇总和分析。

\section{2 结果}

\section{1 物种多样性}

本研究在平潭岛海域所采集底栖贝类标本中, 共鉴定出58科122属161种。其中多板纲1种; 掘足纲 2 科 2 属 2 种; 腹足纲 33 科 57 属 79 种; 双壳纲 22 科 62 属79种。本次研究中有 47 种为平潭岛海域新记录, 如雕刻窦螺 (Sinum incisum)、长角螺 (Hemifusus colosseus)、笠帆螺(Calyptraea morbida)、紫彩血蛤 (Nuttallia olivacea)、施氏獭蛤(Lutraria sieboldii)、 六角角贝(Dentalium hexagonum)等(附录1)。新记录 的物种中, 有 18 种仅采到 1 个标本, 有 8 种每种仅采 到 2 个标本。

结合本研究和历史资料, 平潭岛海域已报道的 底栖贝类共有 98 科244属395种(含种下单位), 剔除 了人为引入的日本黑鲍(Haliotis discus)和皱纹盘鲍 (H. discus hannai) (表1)。其中, 多板纲3科4属4种, 掘足纲3科3属5种, 两纲合计仅占平潭岛海域底栖 贝类总种数的 $2.3 \%$ 。腹足纲有 51 科 114 属 185 种, 分 别占研究区域底栖贝类科、属、种总数的 $52.0 \%$ 、 $46.7 \%$ 和 $46.8 \%$ 。双壳纲种类最为丰富, 共 41 科 123 属201种, 分别占科、属、种总数的 $41.8 \% 、 50.4 \%$ 和 $50.9 \%$ 。

双壳纲中种类最多的科依次为窝蛤科(38种)、
表1 福建平潭岛海域底栖贝类多样性(括号内数值为该类 群占科/属/种总数的百分比)

Table 1 Marine benthic shells diversity in the coast and adjacent area of Pingtan Island, Fujian Province. Numbers in parentheses represent proportions of each component in the total numbers of families, genera or species (\%).

\begin{tabular}{llllll}
\hline 类群 & 多板纲 & 掘足纲 & 腹足纲 & 双壳纲 & 总计 \\
Taxa & Polyplacophora & Scaphopoda & Gastropoda & Bivalvia & Total \\
\hline 科 Family & $3(3.1)$ & $3(3.1)$ & $51(52)$ & $41(41.8)$ & 98 \\
属 Genus & $4(1.6)$ & $3(1.2)$ & $114(46.7)$ & $123(50.4) 244$ \\
种 Species $4(1.0)$ & $5(1.3)$ & $185(46.8)$ & $201(50.9)$ & 395 \\
\hline
\end{tabular}

贻贝科(17种)、樱蛤科(16种)、蚶科(16种)、蛤蜊科 (13种)和扇贝科(10种); 腹足纲中种类最丰富的前 几个科依次为玉螺科(16种)、骨螺科 (16种)、马蹄螺 科(13种)和塔螺科(10种)。述 10 科每个科的种类均 不低于 10 种, 共计 165 种, 占平潭岛海域底栖贝类 总种数的 $41.8 \%$ 。另一方面, 有 71 科在平潭岛海域的 底栖贝类种数不超过 3 种, 其中有 30 科每科仅 1 种, 21 科每科仅 2 种, 20 科每科仅 3 种记录(表 2 )。

在属的水平上, 仅织纹螺科的织纹螺属 (Nassarius, 13种) 超过了 10 种, 另有 5 个属每属种数 不低于5种, 分别为帘蛤科的巴非蛤属 (Paphia, 7种) 和镜蛤属(Dosinia, 5种)、竹蛏科的竹蛏属(Solen, 6 种)、敦螺科的敦螺属(Tonna, 5种)以及蛤蜊科的蛤 蜊属(Mactra, 5种)。共有154属在平潭岛海域每属仅 有1种分布记录。

\section{2 地理分布}

平潭岛海域的 395 种底栖贝类中, 有 370 种 (93.7\%)在南海有分布, 324种(82.0\%)在东海有分布, 123种(31.1\%)在黄渤海有分布, 167种(42.3\%)在台 湾岛东部海域有分布。根据它们在中国近海浅海海 域的分布格局可分为以下6种分布类型(图1):

(I)南海-台湾海峡分布: 共计64种, 占区系总 种数的 $16.2 \%$ 。其中有不少种类在大陆沿海的分布 记录北界止于平潭岛海域, 如葫鸨螺 (Tonna allium)、褶白蚶 (Acar plicata)、大獭蛤 (Lutraria maxima) 等。本文新增记录中有22种属于该分布类 型, 如六角角贝、东方海笋(Pholas orientalis)。

(II) 南海-东海分布: 为平潭岛海域底栖贝类地 理分布的主要类型, 共计197种, 占区系总种数的 $49.9 \%$ 。该分布类型为典型的亚热带性种, 向北延伸 至东海海域, 受长江口的阻碍未能继续北上。如日 本花棘石鳖(Liolophura japonica)、象牙光角贝 
表2 福建平潭岛海域底栖贝类的分类学组成(括号内数值为该纲下的属/种总数)

Table 2 Taxonomic composition of marine benthic shells in the coast and adjacent area of Pingtan Island, Fujian Province. Numbers in parentheses represent the total numbers of genera or species in classes.

\begin{tabular}{|c|c|c|c|c|c|}
\hline 科 Family & 属 Genera & 种 Species & 科 Family & 属 Genera & 种 Species \\
\hline 多板纲 Polyplacophora & (4) & (4) & 50. 敦螺科 Tonnidae & 1 & 5 \\
\hline 1. 毛肤石鳖科 Acanthochitonidae & 1 & 1 & 51. 马蹄螺科 Trochidae & 6 & 13 \\
\hline 2. 石䀉科 Chitonidae & 2 & 2 & 52. 蝶螺科 Turbinidae & 3 & 5 \\
\hline 3. 锉石鳖科 Ischnochitonidae & 1 & 1 & 53. 塔螺科 Turridae & 8 & 10 \\
\hline 掘足纲 Scaphopoda & (3) & (5) & 54. 雉螺科 Turritellidae & 1 & 3 \\
\hline 4. 角贝科 Dentaliidae & 1 & 3 & 55. 蛇螺科 Vermetidae & 3 & 3 \\
\hline 5. 纤细象牙贝科 Gadilinidae & 1 & 1 & 56. 浴螺科 Volutidae & 2 & 2 \\
\hline 6. 光滑象牙贝科 Laevidentaliidae & 1 & 1 & 57. 衣笠螺科 Xenophoridae & 2 & 2 \\
\hline 腹足纲 Gastropoda & (114) & (185) & 双壳纲 Bivalvia & (123) & (201) \\
\hline 7. 笠贝科 Acmaeidae & 3 & 5 & 58. 水鸭蛤科 Anatinellidae & 1 & 1 \\
\hline 8. 轮螺科 Architectonicidae & 1 & 2 & 59. 不等蛤科 Anomiidae & 2 & 2 \\
\hline 9. 拟沼螺科 Assimineidae & 1 & 1 & 60. 蚶科 Arcidae & 8 & 16 \\
\hline 10. 滩栖螺科 Batillariidae & 1 & 3 & 61. 鸟蛤科 Cardiidae & 4 & 7 \\
\hline 11. 蛾螺科 Buccinidae & 2 & 3 & 62. 心蛤科 Carditidae & 1 & 2 \\
\hline 12. 蛙螺科 Bursidae & 1 & 2 & 63. 猿头蛤科 Chamidae & 2 & 3 \\
\hline 13. 丽口螺科 Calliostomatidae & 2 & 2 & 64. 篮蛤科 Corbulidae & 2 & 3 \\
\hline 14. 帆螺科 Calyptraeidae & 2 & 2 & 65. 帽蚶科 Cucullaeidae & 1 & 1 \\
\hline 15. 衲螺科 Cancellariidae & 2 & 2 & 66. 斧蛤科 Donacidae & 1 & 3 \\
\hline 16. 冠螺科 Cassidae & 2 & 3 & 67. 开腹蛤科 Gastrochaenidae & 1 & 1 \\
\hline 17. 蟹守螺科 Cerithiidae & 1 & 1 & 68. 绿螂科 Glauconomidae & 1 & 1 \\
\hline 18. 唇齿螺科 Chilodontaidae & 1 & 1 & 69. 蚶蜊科 Glycymerididae & 1 & 1 \\
\hline 19. 核螺科 Columbellidae & 1 & 3 & 70. 曲蚛科 Gryphaeidae & 1 & 1 \\
\hline 20. 盒螺科 Cylichnidae & 1 & 1 & 71. 钳蛤科 Isognomonidae & 1 & 1 \\
\hline 21. 嵌线螺科 Cymatiidae & 3 & 3 & 72. 拉沙蛤科 Lasaeidae & 1 & 1 \\
\hline 22. 宝贝科 Cypraeidae & 3 & 4 & 73. 鸭嘴蛤科 Laternulidae & 1 & 2 \\
\hline 23. 梯螺科 Epitoniidae & 3 & 4 & 74. 锉蛤科 Limidae & 1 & 1 \\
\hline 24. 光螺科 Eulimidae & 2 & 2 & 75. 满月蛤科 Lucinidae & 1 & 1 \\
\hline 25. 细带螺科 Fasciolariidae & 1 & 2 & 76. 蛤蜊科 Mactridae & 5 & 13 \\
\hline 26. 琵琶螺科 Ficidae & 1 & 2 & 77. 中带蛤科 Mesodesmatidae & 1 & 1 \\
\hline 27. 钥孔䗩科 Fissurellidae & 2 & 3 & 78. 贻贝科 Mytilidae & 10 & 17 \\
\hline 28. 鲍科 Haliotidae & 1 & 1 & 79. 细纹蚶科 Noetiidae & 3 & 3 \\
\hline 29. 阿地螺科 Haminoeidae & 1 & 1 & 80. 牡蚛科 Ostreidae & 6 & 9 \\
\hline 30. 坚琴螺科 Harpidae & 1 & 1 & 81. 扇贝科 Pectinidae & 7 & 10 \\
\hline 31. 滨螺科 Littorinidae & 4 & 4 & 82. 刀蛏科 Pharidae & 3 & 5 \\
\hline 32. 灰螺科 Melongenidae & 2 & 3 & 83. 海笋科 Pholadidae & 4 & 6 \\
\hline 33. 笔螺科 Mitridae & 2 & 2 & 84. 江珧科 Pinnidae & 2 & 3 \\
\hline 34. 骨螺科 Muricidae & 8 & 16 & 85. 海月蛤科 Placunidae & 1 & 1 \\
\hline 35. 花帽贝科 Nacellidae & 1 & 3 & 86. 譬蛤科 Plicatulidae & 1 & 1 \\
\hline 36. 织纹螺科 Nassariidae & 1 & 13 & 87. 紫云蛤科 Psammobiidae & 3 & 7 \\
\hline 37. 玉螺科 Naticidae & 10 & 16 & 88. 珍珠贝科 Pteriidae & 2 & 5 \\
\hline 38. 蜒螺科 Neritidae & 1 & 4 & 89. 双带蛤科 Semelidae & 2 & 3 \\
\hline 39. 榧螺科 Olividae & 3 & 4 & 90. 截蛏科 Solecurtidae & 2 & 2 \\
\hline 40. 梭螺科 Ovulidae & 1 & 2 & 91. 竹蛏科 Solenidae & 1 & 6 \\
\hline 41. 帽贝科 Patellidae & 1 & 1 & 92. 海菊蛤科 Spondylidae & 1 & 2 \\
\hline 42. 皮山螺科 Pisaniidae & 3 & 3 & 93. 樱蛤科 Tellinidae & 14 & 16 \\
\hline 43. 汇螺科 Potamididae & 2 & 3 & 94. 船蛆科 Teredinidae & 1 & 1 \\
\hline 44. 西美螺科 Pseudomelatomidae & 1 & 1 & 95. 色雷西蛤科 Thraciidae & 1 & 1 \\
\hline 45. 小塔螺科 Pyramidellidae & 1 & 2 & 96. 棱蛤科 Trapezidae & 1 & 2 \\
\hline 46. 菊花螺科 Siphonariidae & 1 & 3 & 97. 蹄蛤科 Ungulinidae & 1 & 1 \\
\hline 47. 小阳螺科 Solariellidae & 2 & 2 & 98. 窝蛤科 Veneridae & 20 & 38 \\
\hline 48. 凤螺科 Strombidae & 1 & 1 & 总计 Total & 244 & 395 \\
\hline 49. 笋螺科 Terebridae & 4 & 5 & & & \\
\hline
\end{tabular}


(Laevidentalium eburneum)、杂色鲍 (Haliotis diversicolor)、中国敦螺(Tonna chinensis)、美叶雪蛤 (Clausinella calophylla)、海月(Placuna placenta)等。 本文新增记录中有 18 种属于该分布类型, 如雕刻窦 螺、笠帆螺。

(III)南海-黄渤海分布：种类仅次于上一分布 类型，共计109种，占区系总种数的 $27.6 \%$ 。该分布 类型为广温性种, 如红条毛肤石鳖(Acanthochitona rubrolineata)、嫁䗩 (Cellana toreuma)、扁玉螺 (Neverita didyma)、菲律宾蛤仔(Ruditapes philippinarum)、大竹蛏(Solen grandis)等。其中斯氏无齿 蛤(Anodontia stearnsiana)尚未见东海海域的分布记 录，但在南海和黄渤海均有分布，亦归入此分布类 型。本文新增记录中有4种属于该分布类型, 如紫彩

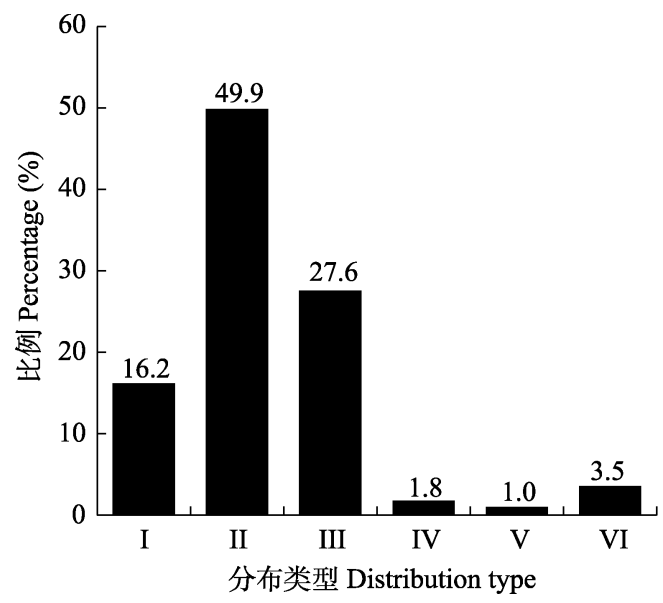

图1 平潭岛海域底栖贝类的地理分布类型。I: 南海-台湾 海峡分布; II: 南海-东海分布; III: 南海-黄渤海分布; IV: 台湾海峡分布; V: 台湾海峡-东海分布; VI: 台湾海峡-黄渤 海分布。

Fig. 1 Geographical distribution types of marine benthic shell species recorded from Pingtan Island and its adjacent waters. I, South China Sea-Taiwan Strait; II, South China Sea-East China Sea; III, South China Sea-Yellow and Bohai seas; IV, Taiwan Strait; V, Taiwan Strait-East China Sea; VI, Taiwan Strait-Yellow and Bohai seas.
血蛤、小楔形蛤(Sunetta solanderii)。

(IV)台湾海峡分布: 目前已知分布局限于台湾 海峡的仅 7 种, 占区系总种数的 $1.8 \%$ 。包括染色笔螺 (Nebularia inquinata)、光螺(Melanella cumingii)、摺 扇笋螺、厚壳敦螺(Tonna tessellata)、长尖石蛏、单 色粘鸟蛤 (Acrosterigma simplex) 以及丽胁线蛤 (Gregariella splendida)。其中染色笔螺也见于台湾 岛东部海域, 光螺也产琉球群岛, 但二者在大陆沿 海浅海地区仅见于台湾海峡。

(V)台湾海峡-东海分布：仅4种, 占区系总种 数的 $1.0 \%$ 。包括矛唇齿螺(Engina lanceolata)、小阳 螺 (Solariella delicata)、扭单齿螺 (Monodonta perplexa)以及布氏尖蛤蜊(Oxyperas bernardi), 其中 后两种为本研究新增记录。

(VI)台湾海峡-黄渤海分布: 共14种, 占区系总 种数的 $3.5 \%$ 。如朝鲜花冠小月螺(Lunella correensis)、 脉红螺(Rapana venosa)、弯竹蛏(Solen tchangi)、白 笠贝(Niveotectura pallida)等。本文新增记录中有 1 种属于该分布类型, 即口马丽螺(Calliostoma koma)。

与研究较为完整的邻近地区区系相比, 平潭岛 海域底栖贝类区系与大陆沿岸地区的关系更为密 切。研究区域产395种底栖贝类中, 有267种(67.6\%) 亦产于南澳及南澎列岛海域, 有228种(57.7\%)在厦 门湾海域有分布, 有 242 种(61.3\%)在洞头及南鹿列 岛海域有分布(表3)。从共有种的类群组成上看, 南 部的两个海域中腹足纲种类的占比略低于双壳纲, 而北部的洞头及南鹿列岛则相反(表3)。相比之下, 平潭岛海域底栖贝类区系与台湾海峡东岸的联系 相对较弱, 其中仅155种(39.2\%)在台湾海峡的澎湖 列岛海域有分布，117种(29.6\%)在台湾岛东北部近 海海域有分布。在共有种的类群组成上, 两个海域 中腹足纲种类的占比均显著高于双壳纲(表3)。在共

表3 福建平潭岛海域与相邻地点的海洋底栖贝类共有种组成(括号内数值为该类群占共有种总数的百分比)

Table 3 Composition of marine benthic shells shared by Pingtan Island, Fujian Province and adjacent sites. Numbers in parentheses represent proportions of each component in the total numbers of shared species (\%).

\begin{tabular}{llllll}
\hline $\begin{array}{l}\text { 类群 } \\
\text { Taxa }\end{array}$ & $\begin{array}{l}\text { 南澳及南澎列岛 } \\
\text { Nan'ao \& Nanpeng Islands }\end{array}$ & $\begin{array}{l}\text { 厦门湾 } \\
\text { Xiamen Bay }\end{array}$ & $\begin{array}{l}\text { 洞头及南鹿列岛 } \\
\text { Dongtou \& Nanji Islands }\end{array}$ & $\begin{array}{l}\text { 澎湖列岛 } \\
\text { Penghu Islands }\end{array}$ & $\begin{array}{l}\text { 台湾岛东北部 } \\
\text { Northeastern Taiwan }\end{array}$ \\
\hline 多板纲 Polyplacophora & $4(1.5)$ & $4(1.8)$ & $4(1.7)$ & $2(1.3)$ & $4(3.4)$ \\
掘足纲 Scaphopoda & $2(0.7)$ & $3(1.3)$ & $2(0.8)$ & 0 & 0 \\
腹足纲 Gastropoda & $121(45.3)$ & $106(46.5)$ & $123(50.8)$ & $90(58.1)$ & $77(65.8)$ \\
双壳纲 Bivalvia & $140(52.4)$ & $115(50.4)$ & $113(46.7)$ & $63(40.6)$ & $36(30.8)$ \\
合计 Total & 267 & 228 & 242 & 155 & 117 \\
\hline
\end{tabular}


有种的分布类型上, 研究区域与上述五个海域的共 有种大部分为 II分布型的种类, 依次占共有种总数 的 $53.2 \% 、 49.6 \% 、 55.0 \% 、 58.1 \%$ 和 $58.1 \%$ 。

\section{3 讨论}

平潭岛海域底栖贝类具典型的亚热带性质, 南 海-东海分布型种类占显著优势, 这与福建沿海软 体动物区系的整体特征基本一致(王方平和黄一鸣, 1993，1994)。南海-台湾海峡分布和南海-东海分布 的暖水性种占区系总种数的 $66 \%$, 这一比例低于南 海大陆沿岸(80\%)而高于东海(56\%) (张胥等, 1963), 表明其区系的过渡性质。东海和南海北部动物区系 通过台湾海峡联系在一起，它们之间有许多共有种， 物种相似度较高, 故同属于印度-西太平洋暖水区 (王颖等, 2013)。在各种中国近海底栖生物地理区划 方案中, 台湾海峡与东海通常被划入同一个地理单 元 如Crame (2000)将其划入 “东中国海区”, 张玺等 (1963)和 Liu（2013)将其划入 “中国-日本亚区”, Bernard等(1993)将其划入东 “中国海省”。徐风山 (1997) 认为, 由于台湾海峡低温的浙闽沿岸流的存 在, 限制了暖水种向北扩张, 因此台湾海峡与东海 以及日本南部归属同一个动物地理省, 与厦门以南 的南海(北部)动物地理省是平行的两个单元。本文 结果显示, 平潭岛海域的底栖贝类区系与南海北部 的南澳及南澎列岛和东海的洞头及南鹿列岛的区 系关系都非常密切, 甚至与前者的共有种略高于后 者。这些共有种大部分属于南海-东海分布的亚热 带性种和南海-黄渤海分布的广温性种。相比之下, 平潭岛海域与台湾岛周边海域的联系相对较弱。因 此, 在台湾海峡内部沿纬度方向分界的生物地理区 划方案(如何利军等, 2021)可能不适用于底栖贝类。

目前有关台湾海峡东岸的底栖贝类区系研究 尚欠缺, 尤其是腹足纲的记录甚少(巫文隆和简士 杰, 2008), 故本文未与该区域的区系作比较。某些 方案中, 澎湖列岛与平潭岛被划入同一地理单元 (张疍等, 1963; Crame, 2000; 何利军等, 2021)。本文 结果显示, 平潭岛海域底栖贝类区系与距离较近的 澎湖列岛区系的共有种远不如南澳及南澎列岛和 洞头及南鹿列岛。平潭岛海域受冬季浙闽低温沿岸 流影响更深, 而澎湖列岛受沿闽浙外海北上的黑潮 分支(台湾暖流)的影响, 冬季水温相对较高(徐凤山 和张均龙, 2018)。因此, 后者的海洋环境与台湾岛
东海岸、兰屿、绿岛更相近，区系中也更多为热带 太平洋种类, 不宜与台湾海峡西岸或台湾岛西岸一 概而论(赖景阳和欧阳盛芝, 1996)。台湾岛东北角受 黑潮暖流主流影响显著, 故虽与平潭岛距离较近, 而二者的底栖贝类区系却相去甚远，和南海南部及 琉球群岛的区系基本上相近(中国自然地理编辑委 员会, 1979)。虽然台湾海峡地区底栖贝类的区系及 其与相邻海域的区划关系尚难以下定论，但平潭岛 海域在海洋环境和种类组成上均与南海和东海大 陆沿岸海域地区更为相似, 这是布庸置疑的。

自王方平和黄一鸣(1993，1994)报道产平潭岛 海域的 250 种底栖贝类以来，同时期出版的《中国海 湾志》第7分册(福建省北部海湾)增补23种(中国海 湾志编纂委员会, 1994), 1997-2018年间出版的《中 国动物志》软体动物门相关卷册中累计增补28种。 本研究报道了 47 种平潭岛海域底栖贝类新记录, 将 该海域底栖贝类的物种多样性记录增加到了 395 种。尽管如此, 平潭岛海域现生底栖贝类的情况还 需深入研究。一方面, 其中约 $71 \%$ 的种类(279种)近 年来也曾在台湾海峡西部海域有报道(黄宗国, 2006; 李荣冠, 2010; 李荣冠等, 2017)。另一方面, 王方平 和黄一鸣(1993，1994)报道的平潭岛海域贝类名录 中, 有21种双壳纲和 22 种腹足纲的种类未见于任何 后续的文献报道中, 如偏胀蚶(Arca ventricosa)、

本日月 月 (Ylistrum japonicum) 、配景轮螺 (Architectonica perspectiva)、坚琴螺(Harpa major) 等。这些种类可能是由于区域环境变化或生物群落 演替而消失的, 它们在平潭岛海域的分布现状还有 待确认。

一些侧重于生态学的研究也在平潭岛海域采 集鉴定了大量的贝类标本。如陈昌生(1992)采集鉴 定了平潭岛海域软体动物106种, 吕小梅等(2008)鉴 定了该海域软体动物44种, 李荣冠(2010)和李荣冠 等(2017)先后在该海域鉴定了软体动物144种和179 种。但这些研究中均未给出该海域物种名录清单, 其中可能包含一些新分布记录。总而言之, 平潭岛 海域的底栖贝类物种多样性还有待完善, 本文的数 据可为后续研究提供参考, 为该海域底栖生物资源 的合理利用和保护提供依据。

致谢: 感谢中山大学国土资源与环境系的宋爽、沈 
嘉聚、郡杏敏、辛悦、菌雨薇、李宝堂、冯汉、苏 广权、罗菊婷在标本制作、鉴定和资料整理过程中 的帮助。

\section{ORCID}

胡亮 (1D) https://orcid.org/0000-0002-5861-633X

\section{参考文献}

Bernard FR, Cai YY, Morton B (1993) Catalogue of the Living Marine Bivalve Molluscs of China. Hong Kong University Press, Hong Kong.

Cai YY (1960) A preliminary investigation on the marine molluscan fauna of Pingtan Island, Fujian. Journal of Jimei Fisheries, 1(2), 1-8. (in Chinese) [蔡英亚 (1960) 福建平 潭岛海产软体动物的初步调查. 集水学报, 1(2), 1-8.]

Cai YY (1966) A preliminary investigation on the Cladocera shells in the coast of Fujian. Chinese Journal of Zoology, 8(2), 76-80. (in Chinese) [ 蔡英亚 (1966) 福建沿海瓣鳃纲 贝类的初步调查. 动物学杂志, 8(2), 76-80.]

Chen CS (1992) Preliminary investigation on benthic ecology in intertidal zone of Haitan Island. Journal of Oceanography in Taiwan Strait, 11, 294-300. (in Chinese with English abstract) [陈昌生 (1992) 海坛岛潮间带底栖生态的初步 调查. 台湾海峡, 11, 294-300.]

Chen ZY (2012) Study on the Taxonomy of Pyramidellidae of China Seas. PhD dissertation, Institute of Oceanology, Chinese Academy of Sciences, Qingdao, Shandong. (in Chinese with English abstract) [陈志云 (2012) 中国海小 塔螺科Pyramidellidae系统分类学研究. 博士学位论文, 中国科学院海洋研究所, 山东青岛.]

Crame JA (2000) Evolution of taxonomic diversity gradients in the marine realm: Evidence from the composition of recent bivalve faunas. Paleobiology, 26, 188-214.

Dong ZZ (2002) Fauna Sinica, Invertebrata, Vol. 29. Science Press, Beijing. (in Chinese) [ 董正之 (2002) 中国动物 志·无脊椎动物, 第二十九卷. 科学出版社, 北京.]

Editorial Committee of China's Bays (1994) China's Bays, Vol. 7. Bays of Northern Fujian. China Ocean Press, Beijing. (in Chinese) [中国海湾志编纂委员会 (1994) 中 国海湾志, 第7分册 (福建省北部海湾). 海洋出版社, 北 京.]

Editorial Committee of Physical Geography of China (1979) Physical Geography of China: Marine Geography. Science Press, Beijing. (in Chinese) [中国自然地理编辑委员会 (1979) 中国自然地理: 海洋地理. 科学出版社, 北京.]

Editorial Committee of Pingtan Local Records (2000) Pingtan Local Records. China Local Records Publishing House, Beijing. (in Chinese) [平潭县地方志编纂委员会 (2000) 平潭县志. 方志出版社, 北京.]

He LJ, Ren HM, Xu SS, Zhang J (2021) Phylogeographic pattern of marine fauna in the Indo-West Pacific.
Oceanologia et Limnologia Sinica, 52, 468-486. (in Chinese with English abstract) [何利军, 任慧敏, 许莎莎, 张经 (2021) 印度洋-西太平洋海洋动物谱系地理演化格局. 海洋与湖沼, 52, 468-486.]

Higo S, Callomon P, Goto Y (1999) Catalogue and Bibliography of the Marine Shell-Bearing Mollusca of Japan. Elle Scientific Publications, Osaka.

Hu CH, Tao HJ (1995) Shells of Taiwan Illustrated in Color. Museum of Natural Science, Taizhong. (in Chinese) [胡忠 恒, 陶锡珍 (1995) 台湾现生贝类彩色图鉴. 自然科学博 物馆, 台中.]

Huang YQ, Li RG, Jiang JX (2009) Biodiversity and distribution of mollusc around the waters of islands, Fujian Province. Marine Sciences, 33(10), 77-83. (in Chinese with English abstract) [黄雅琴, 李荣冠, 江锦祥 (2009) 福建 海岛水域软体动物多样性与分布. 海洋科学, 33(10), 77-83.]

Huang ZG (2006) Diversity of Species in Xiamen Bay, China. China Ocean Press, Beijing. (in Chinese) [黄宗国 (2006) 厦门湾物种多样性. 海洋出版社, 北京.]

Huang ZG, Lin M (2012) The Living Species in China's Seas, Vol. 1. China Ocean Press, Beijing. (in Chinese) [黄宗国, 林茂 (2012) 中国海洋物种多样性(上册). 海洋出版社, 北京.]

Lai KY, Ouyang SC (1996) Molluscan fauna of the Penghu Islands (Pescadores). Annual Taiwan Museum, 39, 315-385. (in Chinese with English abstract) [赖景阳, 欧阳盛芝 (1996) 澎湖群岛的贝类调查报告. 台湾省立博物馆年刊, 39, 315-385.]

Li BQ (2007) Taxonomic and Faunal Study of Turridae (Gastropoda: Neogastropoda) of the China Seas. PhD dissertation, Institute of Oceanology, Chinese Academy of Sciences, Qingdao, Shandong. (in Chinese with English abstract) [李宝泉 (2007) 中国海塔螺科系统分类学和动 物地理学研究. 博士学位论文, 中国科学院海洋研究所, 山东青岛.]

Li FL, Lin MY (2016) Fauna Sinica, Invertebrata, Vol. 55. Science Press, Beijing. (in Chinese) [李风兰, 林民玉 (2016) 中国动物志. 无脊椎动物, 第五十五卷. 科学出版 社, 北京.]

Li RG (2010) Macrobenthos in Fujian Coastal Zone and Western Taiwan Strait. China Ocean Press, Beijing. (in Chinese) [李荣冠 (2010) 福建海岸带与台湾海峡西部海 域大型底栖生物. 海洋出版社, 北京.]

Li RG, Wang JJ, Huang YQ, Lin JH, Lin RS (2017) Intertidal Macrobenthos in Coastal Wetlands, Fujian Province. China Ocean Press, Beijing. (in Chinese) [李荣冠, 王建军, 黄雅 琴, 林俊辉, 林如山 (2017) 福建滨海湿地潮间带大型底 栖生物. 海洋出版社, 北京.]

Liu JY (2013) Status of marine biodiversity of the China Seas. PLoS ONE, 8, e50719.

Lü XM, Fang SH, Zhang YP, Wu PR (2008) Community structure and secondary production of macrobenthos in the 
intertidal zone of Haitan Strait, Fujian Province. Acta Zoologica Sinica, 54, 428-435. (in Chinese with English abstract) [吕小梅, 方少华, 张跃平, 吴萍茹 (2008) 福建 海坛海峡潮间带大型底栖动物群落结构及次级生产力. 动物学报, 54, 428-435.]

Tchang S, Hwang HM (1964) On the Chinese species of Solenidae. Acta Zoologica Sinica, 16, 193-209. (in Chinese with English abstract) [张玺, 黄修明 (1964) 中国海竹蛏 科的研究. 动物学报, 16, 193-209.]

Tchang S, Tsi CY (1962) Economic Fauna of China: Marine Molluscs. Science Press, Beijing. (in Chinese) [张胥, 齐钟 彦 (1962) 中国经济动物志: 海产软体动物. 科学出版 社, 北京.]

Tchang S, Tsi CY, Zhang FS, Ma ST (1963) A preliminary study of the demarcation of marine molluscan faunal regions of China and its adjacent waters. Oceanologia et Limnologia Sinica, 5, 124-138. (in Chinese with English abstract) [张 坌, 齐钟彦, 张福绥, 马绣同 (1963) 中国海软体动物区 系区划的初步研究. 海洋与湖沼, 5, 124-138.]

Wang FP, Huang YM (1993) Studies on the Prosobranchia fauna of Fujian coast. Journal of Fujian Normal University (Natural Science), 9(4), 85-95. (in Chinese with English abstract) [王方平, 黄一鸣 (1993) 福建沿海前鳃类区系 的研究. 福建师范大学学报(自然科学版), 9(4), 85-95.]

Wang FP, Huang YM (1994) Studies on the bivalvia fauna from the Fujian coast. Journal of Fujian Normal University (Natural Science), 10(3), 81-91. (in Chinese with English abstract) [王方平, 黄一鸣 (1994) 福建沿海双壳类区系 的研究. 福建师范大学学报(自然科学版), 10(3), 81-91.]

Wang Y, Liu RY, Su JL (2013) Ocean Geography of China. Science Press, Beijing. (in Chinese) [王颖, 刘瑞玉, 苏纪 兰 (2013) 中国海洋地理. 科学出版社, 北京.]

Wang ZR (1997) Fauna Sinica, Mollusca, Bivalvia, Mytiloida. Science Press, Beijing. (in Chinese) [王祯瑞 (1997) 中国 动物志. 软体动物门.双壳纲.贻贝目. 科学出版社, 北京.]

Wu WL, Jian SJ (2008) The Mollusks of Taoyuan, Hsinchu, and Miaoli Area, Taiwan. Taiwan Forestry Bureau, Taipei. (in Chinese) [巫文隆, 简士杰 (2008) 桃竹苗地区贝类研 究图志. 台湾“农业委员会林务局”, 台北.]

Xu FS (1997) Bivalve Molluscs of China Sea. Science Press, Beijing. (in Chinese) [徐凤山 (1997) 中国海双壳类软体 动物. 科学出版社, 北京.]

Xu FS (2012) Fauna Sinica, Invertebrata, Vol. 48. Science Press, Beijing. (in Chinese) [徐凤山 (2012) 中国动物 志·无脊椎动物, 第四十八卷. 科学出版社, 北京.]

Xu FS, Zhang JL (2018) Fauna Sinica, Invertebrata, Vol. 57. Science Press, Beijing. (in Chinese) [徐凤山, 张均龙
(2018) 中国动物志. 无脊椎动物, 第五十七卷. 科学出版 社, 北京.]

Yang W, Cai YY, Kuang XM (2017) Color Atlas of Molluscs of the South China Sea. China Agriculture Press, Beijing. (in Chinese) [杨文, 蔡英亚, 广雪梅 (2017) 中国南海经济贝 类原色图鉴. 中国农业出版社, 北京.]

Zhang SP (2007) On nine new record species of Ergalataxinae (Gastropoda, Muricidae) from China coast. Oceanologia et Limnologia Sinica, 38, 542-548. (in Chinese with English abstract) [张素萍 (2007) 中国近海爱尔螺亚科九新记录 (腹足纲: 骨螺科). 海洋与湖沼, 38, 542-548.]

Zhang SP (2008) Atlas of Marine Molluscs of China. China Ocean Press, Beijing. (in Chinese) [张素萍 (2008) 中国海 洋贝类图鉴. 海洋出版社, 北京.]

Zhang SP (2016) Fauna Sinica, Invertebrata, Vol. 56. Science Press, Beijing. (in Chinese) [张素萍 (2016) 中国动物 志.无脊椎动物, 第五十六卷. 科学出版社, 北京.]

Zhang SP, Ma XT (2004) Fauna Sinica, Invertebrata, Vol. 34. Science Press, Beijing. (in Chinese) [张素萍, 马绣同 (2004) 中国动物志. 无脊椎动物, 第三十四卷. 科学出版 社, 北京.]

Zhang SP, Zhang JL, Chen ZY, Xu FS (2016) Mollusks of the Yellow Sea and Bohai Sea. Science Press, Beijing. (in Chinese) [张素萍, 张均龙, 陈志云, 徐凤山 (2016) 黄渤 海软体动物图志. 科学出版社, 北京.]

Zhang SQ (2015) Study on the Taxonomy and Zoogeography of the Buccinidae of China Seas. PhD dissertation, Institute of Oceanology, Chinese Academy of Sciences, Qingdao, Shandong. (in Chinese with English abstract) [张树乾 (2015) 中国海蛾螺科Buccinidae系统分类学与动物地理 学研究. 博士学位论文, 中国科学院海洋研究所, 山东青 岛.]

Zheng XD, Qu XC, Zeng XQ, Li Q (2013) Atlas of Aquatic Molluscs in China. Qingdao Publishing House, Qingdao. (in Chinese) [郑小东, 曲学存, 曾晓起, 李琪 (2013) 中国水 生贝类图鉴. 青岛出版社, 青岛.]

Zhong YP, Yang RQ (1996) The new record of Prosobranchia along the Coast of Fujian. Journal of Xiamen Fisheries College, 18(1), 50-54. (in Chinese with English abstract) [钟幼平, 杨瑞琼 (1996) 福建沿海前鳃类软体动物种类 新记录. 厦门水产学院学报, 18(1), 50-54.]

Zhuang QQ (2001) Fauna Sinica, Mollusca, Bivalvia, Veneridae. Science Press, Beijing. (in Chinese) [庄启谦 (2001) 中国动物志. 软体动物门. 双壳纲. 帘蛤科. 科学出 版社, 北京.]

(责任编委: 李新正 责任编辑: 问文杰)

\section{附录 Supplementary Material}

\section{附录1 平潭岛海域底栖贝类名录}

Appendix 1 Checklist of marine benthic shells in the coast and adjacent area of Pingtan Island https://www.biodiversity-science.net/fileup/PDF/2021114-1.pdf 
附录 1 平潭岛海域底栖贝类名录。参考文献: a: 本研究; b: 蔡英亚, 1966; c: 王方平和黄一鸣, 1993; d: 王 方平和黄一鸣, 1994; e: 中国海湾志编纂委员会, 1994; f: 福建省地方志编纂委员会, 2003; g: 黄雅琴等, 2009; h: 中国动物志及卷号 (12: 王祯瑞, 1997; 24: 庄启谦, 2001; 29: 董正之, 2002; 34: 张素萍和马绣同, 2004; 48: 徐凤山, 2012; 56: 张素萍, 2016; 57: 徐凤山和张均龙, 2018); i: 徐凤山, 1997; j: 黄宗国和林茂, 2012; k: 蔡英亚等, 1990; 1: 李凤兰和林民玉, 1999; m: 张素萍, 2007; n: 张树乾和张素萍, 2020; o: 张素萍, 2010; p: 李荣冠, 2010; q: 陈志云, 2012; r: 李宝泉, 2007; s: 张树乾, 2015; t: 杨静文, 20101; u: 李宝泉, 2002²; v: 孙启 梦, 2014; w: 张素萍和尉鹏, 2011; x: 张胥和齐钟彦, 1962; y: 王祯瑞, 1985; $\mathrm{z}$ : 钟幼平和杨瑞琼, 1996.

Appendix 1 Checklist of marine benthic shells in the coast and adjacent area of Pingtan Island. References: a: Present study; b: Cai, 1966; c: Wang \& Huang, 1993; d: Wang \& Huang, 1994; e: Editorial Committee of China Bay Chronicles, 1994; f: Editorial Committee of Fujian Provincial Records, 2003; g: Huang et al, 2009; h: Fauna Sinica with volume number (12: Wang ZR, 1997; 24: Zhuang QQ, 2001; 29: Dong ZZ, 2002; 34: Zhang SP, Ma XT, 2004; 48: Xu FS, 2012; 56: Zhang SP, 2016; 57: Xu FS, Zhang JL, 2018); i: Xu, 1997; j: Huang \& Lin, 2012; k: Cai et al, 1990; 1: Li \& Lin, 1999; m: Zhang, 2007; n: Zhang \& Zhang, 2020; o: Zhang, 2010; p: Li, 2010; q: Chen, 2012; r: Li, 2007; s: Zhang, 2015; t: Yang, 2010; u: Li, 2002²; v: Sun, 2014하 w: Zhang \& Yu, 2011; x: Zhang \& Qi, 1962; y: Wang, 1985; z: Zhong \& Yang, 1996;

\section{多板纲 Polyplacophora \\ 毛肤石鳖科 Acanthochitonidae}

1. 红条毛肤石鳖 Acanthochitona rubrolineata (Lischke, 1873) [k]

石鳖科 Chitonidae

2. 日本花棘石鳖 Liolophura japonica (Lischke, 1873) [a, f, k]

3. 平濑锦石鳖 Onithochiton hirasei Pilsbry, 1901 [f]

锉石鳖科 Ischnochitonidae

4. 朝鲜鳞带石鳖 Lepidozona coreanica (Reeve, 1847) [k]

\section{掘足纲 Scaphopoda}

角贝科 Dentaliidae

5. 喇叭肋角贝 Dentalium buccinulum Gould, 1859 [e]

6. 六角角贝 Dentalium hexagonum Gould, 1859 [a]

7. 肋变角贝 Dentalium octangulatum Donovan, 1804 [e] 纤细象牙贝科 Gadilinidae

8. 胶州湾角贝 Episiphon kiaochowwanense (S. Tchang et C.-Y. Tsi, 1950) [p] 光滑象牙贝科 Laevidentaliidae

9. 象牙光角贝 Laevidentalium eburneum (Linnaeus, 1767) [a]

\section{腹足纲 Gastropoda}

笠贝科 Acmaeidae

10. 白笠贝 Niveotectura pallida (Gould, 1859) [c]

11. 史氏背尖贝 Notoacmea schrenckii (Lischke, 1868) [a, c, k]

\footnotetext{
${ }^{1}$ 杨静文 (2010) 中国海域织纹螺科Nassariidae (Mollusca: Gastropoda) 系统分类学和动物地理学研究. 硕士学位论文, 中国 科学院研究生院, 北京.

2 李宝泉 (2002) 中国海笔螺科的分类学研究. 硕士学位论文, 中国海洋大学, 山东青岛.

3 孙启梦 (2014) 中国海蟹守螺科Cerithiidae的系统分类和动物地理学研究. 硕士学位论文, 中国科学院海洋研究所, 山东青 岛.
} 
12. 矮拟帽贝 Patelloida pygmaea (Dunker, 1860) [c]

13. 琉球拟帽贝 Patelloida ryukyuensis T. Nakano et Ozawa, 2005 [n]

14. 鸟爪拟帽贝 Patelloida saccharina lanx (Reeve, 1855) [a, c, f] 轮螺科 Architectonicidae

15. 鹤鸪轮螺 Architectonica perdix (Hinds, 1844) [a, p]

16. 配景轮螺 Architectonica perspectiva (Linnaeus, 1758) [c] 拟沼螺科 Assimineidae

17. 短拟沼螺 Optediceros breviculum (L. Pfeiffer, 1855) [e] 滩栖螺科 Batillariidae

18. 古氏滩栖螺 Batillaria cumingii (Crosse, 1862) [c, e]

19. 锥形滩栖螺(结节滩栖螺) Batillaria sordida (Gmelin, 1791) [c, f, z]

20. 纵带滩栖螺 Batillaria zonalis (Bruguière, 1792) [a, c, e, k] 蛾螺科 Buccinidae

21. 方斑东风螺 Babylonia areolata (Link, 1807) [a, c, e, g, k, x]

22. 泥东风螺 Babylonia lutosa (Lamarck, 1816) [c, g, k, x]

23. 褐管蛾螺 Siphonalia spadicea (Reeve, 1847) [c, f] 蛙螺科 Bursidae

24. 棘赤蛙螺 Bufonaria perelegans Beu, 1987 [h34]

25. 习见赤蛙螺 Bufonaria rana (Linnaeus, 1758) [a, c, h34, k] 丽口螺科 Calliostomatidae

26. 口马丽螺(口马丽口螺) Calliostoma koma (Shikama et Habe, 1965) [a]

27. 丽口螺(单一丽口螺) Tristichotrochus unicus (Dunker, 1860) [c, h29] 帆螺科 Calyptraeidae

28. 笠帆螺 Calyptraea morbida (Reeve, 1859) [a]

29. 刺履螺(刺靴螺) Crepidula gravispinosa (Kuroda et Habe, 1950) [a, c, j, z] 衲螺科 Cancellariidae

30. 金刚螺(金刚衲螺) Sydaphera spengleriana (Deshayes, 1830) [c, k]

31. 白带三角口螺 Trigonaphera bocageana (Crosse et Debeaux, 1863) [a, c, k] 冠螺科 Cassidae

32. 双沟钼螺 Phalium bisulcatum (Schuber et Wangner, 1829) [a, c, h34, k]

33. 沟纹䯽螺 Phalium strigatum (Gmelin, 1791) [c, h34, k]

34. 球䭮螺 Semicassis bisulcata (Schubert et J. A. Wagner, 1829) [x]

蟹守螺科 Cerithiidae

35. 蕾丝蟹守螺 Cerithium dialeucum Phillippi, 1849 [v] 唇齿螺科 Chilodontaidae

36. 粗精真蹄螺 Euchelus scaber (Linnaeus, 1758) [c, f] 核螺科 Columbellidae

37. 丽核螺 Mitrella albuginosa (Reeve, 1859) [c, e, k]

38. 双带核螺(双带小笔螺) Mitrella bicincta (Gould, 1860) [z]

39. 布尔核螺 Mitrella burchardi (Dunker, 1877) [c]

$$
\text { 盒螺科 Cylichnidae }
$$

40. 圆筒原盒螺 Cylichna biplicata (A. Adams in Sowerby, 1850) [p] 嵌线螺科 Cymatiidae

41. 圆肋嵌线螺 Cymatium cutaceum (Lamarck, 1816) [h34] 
42. 粒蝌蚪螺(粒神螺) Gyrineum natator (Röding, 1798) [a, c, e, h34, k]

43. 环沟嵌线螺(尾嵌线螺) Linatella caudata (Gmelin, 1791) [c]

宝贝科 Cypraeidae

44. 玛瑙拟春贝 Erronea onyx (Linnaeus, 1758) [c, j, k, w]

45. 秘斑眼球贝 Naria miliaris (Gmelin, 1791) [c]

46. 紫眼球贝 Naria poraria (Linnaeus, 1758) [c]

47. 细焦掌贝(日本细焦掌贝) Purpuradusta gracilis (Gaskoin, 1849) [c, k] 梯螺科 Epitoniidae

48. 尖高旋螺 Acrilla acuminata (G.B. Sowerby II, 1844) [a, c, e, k]

49. 日本棘梯螺 Epitonium japonicum (Dunker, 1861) [c]

50. 梯螺 Epitonium scalare (Linnaeus, 1758) [c]

51. 迷乱环肋螺 Gyroscala commutata (Monterosato, 1877) [z] 光螺科 Eulimidae

52. 双带瓷光螺 Eulima bifascialis (A. Adams, 1863) [p]

53. 光螺 Melanella cumingii (A. Adams, 1854) [z] 细带螺科 Fasciolariidae

54. 塔形纺锤螺 Fusinus forceps (Perry, 1811) [c, k]

55. 长尾纺锤螺 Fusinus longicaudus (Lamarck, 1816) [a, c] 琵琶螺科 Ficidae

56. 白带琵琶螺 Ficus ficus (Linnaeus, 1758) [a, c, h34, k, x;z]

57. 长琵琶螺 Ficus gracilis (G.B. Sowerby I, 1825) [h34, k] 钥孔䗩科 Fissurellidae

58. 鼠眼孔䗩 Diodora mus (Reeve, 1850) [a, c]

59. 勒氏孔䗩(瑞氏眼孔䗩) Diodora reevei (Schepman, 1908) [a]

60. 中华盾䗩 Scutus sinensis (Blainville, 1825) [c, k]

鲍科 Haliotidae

* 日本黑鲍 Haliotis discus Reeve, 1846 [z] 引入种

* 皱纹盘鲍 Haliotis discus hannai Ino, 1953 [a] 引入种

61. 杂色鲍 Haliotis diversicolor Reeve, 1846 [c, f, k]

阿地螺科 Haminoeidae

62. 泥螺 Bullacta caurina (Benson, 1842) [e, k]

$$
\text { 坚琴螺科 Harpidae }
$$

63. 坚琴螺 Harpa major Röding, 1798 [c]

滨螺科 Littorinidae

64. 塔结节滨螺(平凡屋顶螺) Echinolittorina pascua (Rosewater, 1970) [c, k]

65. 粗粘拟滨螺(粗糙滨螺) Littoraria scabra (Linnaeus, 1758) [c]

66. 短滨螺 Littorina brevicula (Philippi, 1844) [c, k]

67. 粒结节滨螺(粒屋顶螺) Nodilittorina radiata (Souleyet, 1852) [c, k] 盔螺科 Melongenidae

68. 细角螺 Brunneifusus ternatanus (Gmelin, 1791) [c, k]

69. 长角螺(大角螺) Hemifusus colosseus (Lamarck, 1816) [a]

70. 管角螺 Hemifusus tuba (Gmelin, 1791) [a, c, g, k] 笔螺科 Mitridae

71. 中国笔螺 Isara chinensis (Gray, 1834) [c, k, u] 
72. 染色笔螺(色笔螺) Nebularia inquinata (Reeve, 1844) [c, u]

$$
\text { 骨螺科 Muricidae }
$$

73. 亚洲棘螺 Chicoreus asianus Kuroda, 1942 [a, c, k]

74. 焦棘螺 Chicoreus torrefactus (G. B. Sowerby II, 1841) [c]

75. 蚛敌荔枝螺 Indothais gradata (Jonas, 1846) [c, k]

76. 钩棘骨螺 Murex aduncospinosus G. B. Sowerby II, 1841 [c, f, z]

77. 栉棘骨螺 Murex pecten Lightfoot, 1786 [c]

78. 浅缝骨螺 Murex trapa Röding, 1798 [a, c, e, k]

79. 无花果奥兰螺 Orania ficula (Reeve, 1848) [m]

80. 铅色奥兰螺 Orania livida (Reeve, 1846) [m]

81. 红螺(皱红螺) Rapana bezoar (Linnaeus, 1767) [c, e, f, k, x]

82. 梨形红螺 Rapana rapiformis (Born, 1778) [c, f]

83. 脉红螺 Rapana venosa (Valenciennes, 1846) [a, c, e, f]

84. 瘤荔枝螺 Reishia bronni (Dunker, 1860) [c, f]

85. 疮荔枝螺 Thais clavigera Küster, 1860 [a, c, e, k]

86. 爪哇荔枝螺 Thais javanica (Philippi, 1848) [a]

87. 黄口荔枝螺 Thais luteostoma (Holten, 1803) [a, c, k]

88. 直吻骨螺 Vokesimurex rectirostris (G. B. Sowerby II, 1841) [c, f] 花帽贝科 Nacellidae

89. 斗嫁䗩 Cellana grata (Gould, 1859) [a, c]

90. 龟甲蜮 Cellana testudinaria (Linnaeus, 1758) [a]

91. 嫁䗩 Cellana toreuma (Reeve, 1854) [a, c, f, k]

织纹螺科 Nassariidae

92. 方形织纹螺(缝合海因螺) Nassarius acuminatus (Marrat, 1880) [c, f, s]

93. 雕刻织纹螺 Nassarius caelatus (A. Adams, 1852) [c]

94. 方格织纹螺 Nassarius conoidalis (Deshayes, 1832) [a, k]

95. 秀丽织纹螺 (习见织纹螺) Nassarius festivus (Powys, 1835) [c, e, k]

96. 节织纹螺 Nassarius hepaticus (Pulteney, 1799) [a, c, k, t]

97. 爪哇织纹螺 Nassarius javanus (Schepman, 1891) [t]

98. 暗色织纹螺(胆形织纹螺) Nassarius pullus (Linnaeus, 1758) [c, k]

99. 光织纹螺 Nassarius rutilans (Reeve) [c]

100. 半褶织纹螺 Nassarius sinarum (Philippi, 1851) [a, c, t]

101. 西格织纹螺 Nassarius siquijorensis (A. Adams, 1852) [c, e, k]

102. 红带织纹螺 Nassarius succinctus (A. Adams, 1852) [c, k]

103. 扩张织纹螺 Nassarius sufflatus (Gould, 1860) [o, t]

104. 纵肋织纹螺 Nassarius variciferus (A. Adams, 1852) [a, c]

玉螺科 Naticidae

105. 乳头真玉螺(真玉螺) Eunaticina papilla (Gmelin, 1791) [a, c, h56]

106. 福氏玉螺 Euspira gilva (Philippi, 1851) [x]

107. 广大扁玉螺 Glossaulax didyma ampla (Philippi, 1849) [f]

108. 囊形扁玉螺 Glossaulax vesicalis (Philippi, 1848) [h56]

109. 微黄镰玉螺 Lunatica gilva (Philippi, 1851) [a, c, e, h56]

110. 黑田乳玉螺(大口乳玉螺) Mammilla kurodai (Iw. Taki, 1944) [a, h56]

111. 双带玉螺 Natica bibalteata (Linnaeus, 1758) [h56] 
112. 线纹玉螺 Natica lineata (Röding, 1798) [a, c, f, h56, k]

113. 褐玉螺 Natica spadicea (Gmelin, 1791) [c]

114. 玉螺 Natica vitellus (Linnaeus, 1758) [a]

115. 扁玉螺 Neverita didyma (Röding, 1798) [a, c, e, h56, k, x]

116. 斑玉螺 Paratectonatica tigrina (Röding, 1798) [c, e, h56, k, x]

117. 乳玉螺 Polynices mammatus (Röding, 1798) [a, c, f, k]

118. 扁平窦螺 Sinum haliotoideum (Linnaeus, 1758) [h56]

119. 雕刻窦螺 Sinum incisum (Reeve, 1864) [a]

120. 爪哇窦螺 Sinum javanicum (Gray, 1834) [c, h56, k] 蜒螺科 Neritidae

121. 渔舟蜒螺 Nerita albicilla Linnaeus, 1758 [a, c, f, k]

122. 矮狮蜒螺(变色蜒螺) Nerita chamaeleon Linnaeus, 1758 [a]

123. 日本蜒螺 Nerita japonica Dunker, 1860 [c]

124. 齿纹蜒螺 Nerita yoldii Récluz, 1841 [k]

榧螺科 Olividae

125. 龙宫弹头螺(红侍女螺) Amalda rubiginosa (Swainson, 1823) [c]

126. 伶鼠榧螺 Oliva mustelina Lamarck, 1811 [a, c, g, k, p, x]

127. 细小榧螺 Olivella lepta (Duclos, 1835) [a, c, k, z]

128. 平小榧螺 Olivella plana (Marrat, 1871) [a]

梭螺科 Ovulidae

129. 短喙骗梭螺 Phenacovolva brevirostris (Schumacher, 1817) [c]

130. 白带骗梭螺 Phenacovolva dancei C.N. Cate, 1973 [c, k] 帽贝科 Patellidae

131. 星状帽贝 Scutellastra flexuosa (Quoy et Gaimard, 1834) [a, c, f, j] 皮山螺科 Pisaniidae

132. 甲虫螺 Cantharus cecillei (Philippi, 1844) [a, c, k, s]

133. 矛唇齿螺 Engina lanceolata (Kuroda et Habe, 1971) [e]

134. 粗纹蛾螺(波纹甲虫螺) Pollia undosa (Linnaeus, 1758) [z]

汇螺科 Potamididae

135. 彩拟蟹守螺 Cerithidea balteata A. Adams, 1855 [e]

136. 小翼拟蟹守螺 Cerithidea microptera (Kiener, 1842) [a, c]

137. 珠带拟蟹守螺 Pirenella cingulata (Gmelin, 1791) [c, e, k] 西美螺科 Pseudomelatomidae

138. 旗短口螺 Ptychobela vexillium (Habe et Kosuge, 1966) [e] 小塔螺科 Pyramidellidae

139. 高小塔螺(高捻塔螺) Monotygma eximia (Lischke, 1872) [q]

140. 细肋捻塔螺 Monotygma tenuilirata Chen 2012 [q] 菊花螺科 Siphonariidae

141. 黑菊花螺 Siphonaria atra Quoy et Gaimard, 1833 [a]

142. 日本菊花螺 Siphonaria japonica (Donovan, 1824) [a, f, k]

143. 黑褐菊花螺(蛛形菊花螺) Siphonaria sirius Pilsbry, 1894 [a] 小阳螺科 Solariellidae

144. 中国小铃螺 Minolia chinensis G. B. Sowerby III, 1889 [c, f]

145. 小阳螺 Solariella delicata Dall, 1919 [e] 


\section{凤螺科 Strombidae}

146. 强缘风螺 Margistrombus robustus (G.B. Sowerby III, 1875) [c, h56, k]

笋螺科 Terebridae

147. 双层螺 Duplicaria duplicata (Linnaeus, 1758) [a, e]

148. 平户双层螺 Duplicaria hiradoensis (Pilsbry, 1921) [1]

149. 棒矛螺 Hastula bacillus (Deshayes, 1859) [1]

150. 摺扇笋螺 Punctoterebra nitida (Hinds, 1844) [z]

151. 三列笋螺 Terebra triseriata Gray, 1834 [c]

\section{敦螺科 Tonnidae}

152. 葫㝄螺 Tonna allium (Dillwyn, 1817) [a]

153. 中国敦螺(丽敦螺) Tonna chinensis (Dillwyn, 1817) [c, f, h34, k, x]

154. 带敦螺 Tonna galea (Linnaeus, 1758) [a, c, f]

155. 沟敦螺 Tonna sulcosa (Born, 1778) [a, c, g, k]

156. 厚壳敦螺 Tonna tessellata (Lamarck, 1816) [c, f]

马蹄螺科 Trochidae

157. 斑隐螺 Clanculus stigmatarius A. Adams, 1853 [c, f]

158. 古琴多子螺(古琴拟口螺) Granata lyrata (Pilsbry, 1890) [a]

159. 单齿螺 Monodonta labio (Linnaeus, 1758) [a, c, h29, k, x]

160. 拟蜒单齿螺 Monodonta neritoides (Philippi, 1849) [a]

161. 扭单齿螺 Monodonta perplexa Pilsbry, 1889 [a]

162. 银口凹螺 Tegula argyrostoma (Gmelin, 1791) [a, c, h29, k, x]

163. 黑凹螺 Tegula nigerrima (Gmelin, 1791) [c, h29]

164. 锈凹螺 Tegula rustica (Gmelin, 1791) [a, c, h29, k, x]

165. 马蹄螺 Trochus maculatus Linnaeus, 1758 [c, f, k]

166. 齿轮马蹄螺 Trochus rota Dunker, 1860 [c, f]

167. 肋䗉螺 Umbonium costatum (Kiener, 1839) [a, c, e, f, h29]

168. 托氏䗉螺 Umbonium thomasi (Crosse, 1863) [a, c]

169. 䗉螺 Umbonium vestiarium (Linnaeus, 1758) [a, c, f, k]

蝾螺科 Turbinidae

170. 红底星螺(紫底星螺) Astralium haematragum (Menke, 1829) [a, c, h29, k]

171. 朝鲜花冠小月螺 Lunella correensis (Récluz, 1853) [c, f, k]

172. 粒花冠小月螺 Lunella granulata (Gmelin, 1791) [a, c, h29, k]

173. 节蝾螺 Turbo articulatus Reeve, 1848 [c, f, k]

174. 角蝾螺 Turbo cornutus Lightfoot, 1786 [a, c, h29, k]

\section{塔螺科 Turridae}

175. 川村短口螺 Cheungbeia kawamurai Habe et Kosuge, 1966 [a]

176. 黄短口螺 Clathrodrillia flavidula (Lamarck, 1822) [c, e, k]

177. 美丽蕾螺 Gemmula speciosa (Reeve, 1842) [e]

178. 黑田短口螺 Inquisitor kuroodai (Habe et Kosuge, 1966) [a]

179. 假主棒螺 Inquisitor pseudoprincipalis (Yokoyama, 1920) [c, e, k, r]

180. 白龙骨乐飞螺 Lophiotoma leucotropis (A. Adams et Reeve, 1850) [a, c, e, k]

181. 细长克拉螺 Paraclathurella gracilenta (Reeve, 1843) [r]

182. 爪哇拟塔螺 Turricula javana (Linnaeus, 1767) [a, c]

183. 假奈拟塔螺 Turricula nelliae spuria (Hedley, 1922) [a, c, e] 
184. 细肋蕾螺 Unedogemmula deshayesii (Doumet, 1840) [c] 雉螺科 Turritellidae

185. 棒雉螺 Turritella bacillum Kiener, 1843 [c, g, k]

186. 带雉螺 Turritella cingulifera G. B. Sowerby I, 1825 [c, f]

187. 笋雉螺 Turritella terebra (Linnaeus, 1758) [a, c, f]

\section{蛇螺科 Vermetidae}

188. 大管蛇螺 Ceraesignum maximum (G.B. Sowerby I, 1825) [a]

189. 覆瓦小蛇螺 Thylacodes adamsii (Mörch, 1859) [a, c, k]

190. 紧卷蛇螺 Vermetus renisectus (Carpenter, 1857) [a, k]

浴螺科 Volutidae

191. 电光螺 Fulgoraria rupestris (Gmelin, 1791) [c]

192. 瓜螺 Melo melo (Lightfoot, 1786) [c, f, k]

衣笠螺科 Xenophoridae

193. 光衣笠螺 Onustus exuta (Reeve, 1842) [a, k]

194. 中华衣笠螺(砾壳衣笠螺) Stellaria sinensis (Philippi, 1841) [a]

\section{双壳纲 Bivalvia}

水鸭蛤科 Anatinellidae

195. 鸟喙小脆蛤 Raeta pulchella (A. Adams et Reeve, 1850) [p] 不等蛤科 Anomiidae

196. 中国不等蛤 Anomia chinensis Philippi, 1849 [d]

197. 难解不等蛤 Enigmonia aenigmatica (Holten, 1802) [d, e]

蚶科 Arcidae

198. 褶白蚶 Acar plicata (Dillwyn, 1817) [i, j, k]

199. 毛蚶 Anadara kagoshimensis (Tokunaga, 1906) [d, x]

200. 赛氏毛蚶 Anadara satowi (Dunker, 1882) [d, i, j]

201. 布氏蚶 Arca boucardi Jousseaume, 1894 [a, b, d, i]

202. 偏胀蚶 Arca ventricosa Lamarck, 1819 [d]

203. 双纹须蚶 Barbatia bistrigata (Dunker, 1866) [a, d, f]

204. 青蚶 Barbatia virescens (Reeve, 1844) [a, b, d, e, k, x]

205. 斑顶须蚶 Mesocibota signata (Dunker, 1868) [i, j]

206. 不等壳毛蚶 Scapharca inaequivalvis Bruguière, 1789 [a]

207. 日本毛蚶 Scapharca japonica (Reeve, 1844) [d, e, f, i, j]

208. 唇毛蚶 Scapharca labiosa (G.B. Sowerby I, 1833) [a, d, f]

209. 泥蚶 Tegillarca granosa (Linnaeus, 1758) [a, b, d, k, x]

210. 结蚶 Tegillarca nodifera Martens, 1860 [a, d, k]

211. 鳞片扭蚶 Trisidos kiyonoi (Makiyama, 1931) [i, j, k]

212. 半扭䖵 Trisidos semitorta (Lamarck, 1819) [a]

213. 扭蚶 Trisidos tortuosa (Linnaeus, 1758) [d]

\section{鸟蛤科 Cardiidae}

214. 粗䊁鸟蛤 Acrosterigma impolitum (G.B. Sowerby II, 1834) [d, f]

215. 单色䊁鸟蛤 Acrosterigma simplex (Spengler, 1799) [h48]

216. 隆脊鸟蛤 Fragum carinatum (Lynge, 1909) [d, f]

217. 砂粘鸟蛤(沙粘鸟蛤) Trachycardium arenicolum (Reeve, 1845) [a, b, d, f, h48, j] 
218. 亚洲鸟蛤 Vepricardium asiaticum (Bruguière, 1789) [d]

219. 多刺鸟蛤 Vepricardium multispinosum (G.B. Sowerby II, 1839) [a]

220. 中华鸟蛤 Vepricardium sinense (G.B. Sowerby II, 1839) [a, d] 心蛤科 Carditidae

221. 斜纹心蛤 Cardita leana Dunker, 1860 [a, h48]

222. 异纹心蛤 Cardita variegata Bruguière, $1792[\mathrm{~b}, \mathrm{~d}, \mathrm{k}]$ 猿头蛤科 Chamidae

223. 敦氏猿头蛤(半紫猿头蛤) Chama dunkeri Lischke, $1870[\mathrm{~b}, \mathrm{~d}, \mathrm{j}]$

224. 太平洋猿头蛤(扭曲猿头蛤) Chama pacifica Broderip, 1835 [d, i, j, k]

225. 反转拟猿头蛤 Pseudochama retroversa (Lischke, 1870) [i, j] 篮蛤科 Corbulidae

226. 光滑河篮蛤 Potamocorbula laevis (Hinds, 1843) [d, e]

227. 红齿硬篮蛤 Solidicorbula erythrodon (Lamarck, 1818) [a, d]

228. 衣硬篮蛤 Solidicorbula tunicata (Hinds, 1843) [a]

帽蚶科 Cucullaeidae

229. 粒帽蚶 Cucullaea granulosa Jonas, 1846 [d, f] 斧蛤科 Donacidae

230. 楔形斧蛤 Donax cuneatus Linnaeus, 1758 [a, d, j]

231. 狄氏斧蛤 Donax incarnatus Gmelin, 1791 [d]

232. 紫藤斧蛤 Donax semigranosus Dunker, 1877 [a, d] 开腹蛤科 Gastrochaenidae

233. 多粒开腹蛤 Eufistulana grandis (Deshayes, 1855) [d] 绿螂科 Glauconomidae

234. 中国绿螂 Glauconome chinensis Gray, 1828 [e] 蚶蜊科 Glycymerididae

235. 衣蚶蜊 Glycymeris vestita (Dunker, 1877) [a, d, i, j] 曲蚄科 Gryphaeidae

236. 舌骨牡蚛 Hyotissa hyotis (Linnaeus, 1758) [a, d] 钳蛤科 Isognomonidae

237. 豆英钳蛤 Isognomon legumen (Gmelin, 1791) $[\mathrm{d}, \mathrm{j}, \mathrm{k}]$ 拉沙蛤科 Lasaeidae

238. 拟斧蛤(长圆拟斧蛤) Nipponomysella oblongata (Yokoyama, 1922) [p] 鸭嘴蛤科 Laternulidae

239. 剖刀鸭嘴蛤 Laternula boschasina (Reeve, 1860) [d]

240. 渤海鸭嘴蛤 Laternula gracilis (Reeve, 1860) [b, d, e, k] 锉蛤科 Limidae

241. 函馆雪锉蛤(函馆锉蛤) Limaria hakodatensis (Tokunaga, 1906) [e] 满月蛤科 Lucinidae

242. 斯氏无齿蛤(满月无齿蛤) Anodontia stearnsiana (Oyama, 1954) [d] 蛤蜊科 Mactridae

243. 奇獭蛤 Lutraria impar Reeve, 1854 [j]

244. 大獭蛤 Lutraria maxima Jonas, 1844 [j]

245. 菲律宾獭蛤(弓獭蛤) Lutraria rhynchaena Jonas, 1844 [d, f, j]

246. 施氏獭蛤 Lutraria sieboldii Reeve, 1854 [a] 
247. 西施舌 Mactra antiquata Spengler, 1802 [d, e, g, k, x]

248. 中国蛤蜊 Mactra chinensis Philippi, 1846 [d, g]

249. 楔蛤蜊 Mactra cuneata Gmelin, 1791 [a]

250. 平蛤蜊 Mactra mera Reeve, 1854 [a]

251. 四角蛤蜊 Mactra quadrangularis Reeve, 1854 [d, e, k]

252. 角小蛤蜊 Mactrotoma angulifera (Reeve, 1854) [j]

253. 透明立蛤 Meropesta pellucida (Gmelin, 1791) [j]

254. 中日立蛤 Meropesta sinojaponica Zhuang, 1983 [d]

255. 布氏尖蛤蜊(巴氏长轴蛤) Oxyperas bernardi (Pilsbry, 1904) [a]

中带蛤科 Mesodesmatidae

256. 锈色朽叶蛤 Coecella turgida Deshayes, 1855 [a, d]

贻贝科 Mytilidae

257. 凸壳肌蛤 Arcuatula senhousia (Benson, 1842) [b, d, e, k]

258. 丽肋线蛤(丽肋线贻贝) Gregariella splendida (Reeve, 1858) [i, j]

259. 长尖石蛏 Leiosolenus lepteces (Wang, 1997) [h12, j]

260. 短石蛏 Leiosolenus lischkei M. Huber, 2010 [b, d, h12, i, k]

261. 细尖石蛏 Leiosolenus mucronatus (Philippi, 1846) [h12]

262. 耳偏顶蛤 Modiolus auriculatus (Krauss, 1848) [h12, i, j]

263. 带偏顶蛤(须偏顶蛤) Modiolus comptus (G.B. Sowerby III, 1915) [a, b, d, h12]

264. 麦氏偏顶蛤(角偏顶蛤) Modiolus modulaides (Röding, 1798) [b, d, h12, k]

265. 菲律宾偏顶蛤 Modiolus philippinarum (Hanley, 1843) [d]

266. 心形肌蛤 Musculus cumingianus (Reeve, 1857) [h12, i, j, k]

267. 紫贻贝 Mytilus galloprovincialis Lamarck, 1819 [a, d]

268. 厚壳贻贝 Mytilus unguiculatus Valenciennes, 1858 [b, d, h12, i, j, x]

269. 翡翠贻贝(翡翠股贻贝) Perna viridis (Linnaeus, 1758) [a, h12]

270. 隆起隔贻贝 Septifer excisus (Wiegmann, 1837) [d]

271. 条纹隔贻贝 Septifer virgatus (Wiegmann, 1837) [a, b, d, f, h12, k]

272. 毛贻贝(栉毛短齿蛤) Trichomya hirsuta (Lamarck, 1819) [a, b, d, f, h12, i, k]

273. 黑菾麦蛤(黑偏顶蛤) Xenostrobus atratus (Lischke, 1871) [b, d, e, k]

细纹蚶科 Noetiidae

274. 棕栉毛蚶(褐蚶) Didimacar tenebrica (Reeve, 1844) [a, b, d, k]

275. 橄榄蚶 Estellacar olivacea (Reeve, 1844) [b, d]

276. 对称拟蚶 Striarca symmetrica (Reeve, 1844) [d, f, k]

牡蚛科 Ostreidae

277. 褶牡蚛 Alectryonella plicatula (Gmelin, 1791) [b, k]

278. 近江巨牡蚛(近江牡蚛) Crassostrea ariakensis (Fujita, 1913) [a, d]

279. 长牡蚛 Crassostrea gigas (Thumberg, 1793) [a,d]

280. 齿牡蚛(薄片牡蚛) Dendostrea folium (Linnaeus, 1758) [a]

281. 密鳞牡蚛 Ostrea denselamellosa Lischke, 1869 [a, b, d, k]

282. 棘刺牡蚛 Saccostrea echinata (Quoy et Gaimard, 1835) [a, b, d, k]

283. 团聚告蛎 Saccostrea glomerata (Gould, 1850) [d]

284. 刺牡蚛(僧帽牡蚛) Saccostrea kegaki Torigoe et Inaba, 1981 [d, x]

285. 猫爪牡蚛 Talonostrea talonata Li et Qi, 1994 [a, d, f] 
286. 栉孔扇贝 Azumapecten farreri (Jones et Preston, 1904) [a, d]

287. 异纹栉孔扇贝 Chlamys irregularis (G.B. Sowerby II, 1842) [a, d, f, i, k]

288. 鳞锦海扇 Chlamys squamata (Gmelin, 1791) [a]

289. 优拟套扇贝 Excellichlamys spectabilis (Reeve, 1853) [i, y]

290. 白条类栉孔扇贝(白条栉孔扇贝) Mimachlamys albolineata (G.B. Sowerby II, 1842) [a]

291. 华贵类栉孔扇贝 Mimachlamys crassicostata (G.B. Sowerby II, 1842) [d]

292. 嵌条扇贝 Pecten albicans (Schröter, 1802) [b, d, f, k]

293. 箱型扇贝(箱型栉孔扇贝) Pecten pyxidatus (Born, 1778) [a, b, d, i, k]

294. 新加坡掌扇贝(花鹊栉孔扇贝) Volachlamys singaporina (G.B. Sowerby II, 1842) [b, d, k]

295. 日本日月贝 Ylistrum japonicum (Gmelin, 1791) [d]

\section{刀蛏科 Pharidae}

296. 小刀蛏 Cultellus attenuatus Dunker, 1862 [a, b, d, k]

297. 尖刀蛏 Cultellus subellipticus Dunker, $1862[\mathrm{e}, \mathrm{g}]$

298. 小荚蛏 Siliqua minima (Gmelin, 1791) [d]

299. 辐射荚蛏 Siliqua radiata (Linnaeus, 1758) [d]

300. 缢蛏 Sinonovacula constricta (Lamarck, 1818) [a, b, d, e, x] 海笋科 Pholadidae

301. 全海笋 Barnea australasiae (G.B. Sowerby II, 1849) [e, j, k]

302. 脆壳全海笋 Barnea fragilis (G.B. Sowerby II, 1849) [b, i, k]

303. 马尼拉海笋 Barnea manilensis (Philippi, 1847) [a, d]

304. 马特海笋 Martesia striata (Linnaeus, 1758) [d]

305. 波纹沟海笋 Penitella gabbii (Tryon, 1863) [b, d]

306. 东方海笋 Pholas orientalis Gmelin, 1791 [a]

江珧科 Pinnidae

307. 栉江珧 Atrina pectinata (Linnaeus, 1767) [b, d, g, k]

308. 羽状江珧 Atrina penna (Reeve, 1858) [b, d, f]

309. 细长裂江珧 Pinna attenuata Reeve, 1858 [d, f]

海月蛤科 Placunidae

310. 海月 Placuna placenta (Linnaeus, 1758) [b, d, x] 譬蛤科 Plicatulidae

311. 简易譬蛤 Plicatula regularis Philippi, 1849 [a]

紫云蛤科 Psammobiidae

312. 长紫蛤(紫蛤) Gari elongata (Lamarck, 1818) [d, f]

313. 射带紫云蛤 Gari radiata (Dunker in Philippi, 1845) [d]

314. 截形紫云蛤 Gari truncata (Linnaeus, 1767) [a]

315. 绿紫蛤 Gari virescens (Deshayes, 1855) [d, f]

316. 中国紫蛤 Hiatula chinensis (Mörch, 1853) [a, b, d, f, k]

317. 双线紫蛤 Hiatula diphos (Linnaeus, 1771) [b, d]

318. 紫彩血蛤 Nuttallia olivacea (Jay, 1857) [a]

珍珠贝科 Pteriidae

319. 长耳珠母贝 Pinctada chemnitzii (Philippi, 1849) [d, f]

320. 马氏珠母贝(合浦珠母贝) Pinctada imbricata Röding, 1798 [b, d]

321. 珠母贝 Pinctada margaritifera (Linnaeus, 1758) [d, f]

322. 美丽珍珠贝 Pteria formosa (Reeve, 1857) [d, f] 
323. 短翼珍珠贝 Pteria heteroptera (Lamarck, 1819) [d, f]

双带蛤科 Semelidae

324. 小月阿布蛤 Abra lunella (Gould, 1861) [p]

325. 索纹双带蛤(中华双带蛤) Semele cordiformis (Holten, 1802) [b, h57]

326. 粗纹双带蛤 Semele scabra (Hanley, 1843) [d]

截蛏科 Solecurtidae

327. 狭仿䍀蛏(狭佐吉蛤) Azorinus coarctatus (Gmelin, 1791) [a]

328. 总角截蛏 Solecurtus divaricatus (Lischke, 1869) [a, d]

竹蛏科 Solenidae

329. 短竹蛏 Solen brevissimus Martens, 1865 [d, f, g]

330. 赤竹蛏 Solen gordonis Yokoyama, 1920 [d, f]

331. 大竹蛏 Solen grandis Dunker, 1861 [a, b, d, k, x]

332. 紫斑竹蛏 Solen sloanii Gray, 1843 [a]

333. 长竹蛏 Solen strictus Gould, 1861 [b, d]

334. 弯竹蛏 Solen tchangi M. Huber, 2010 [e]

海菊蛤科 Spondylidae

335. 尼科巴海菊蛤 Spondylus nicobaricus Schreibers, 1793 [a, d, k]

336. 棘刺海菊蛤 Spondylus spinosus Schreibers, 1793 [d]

樱蛤科 Tellinidae

337. 矛角樱蛤(被角樱蛤) Angulus lanceolatus (Gmelin, 1791) [e, h57]

338. 衣角樱蛤(衣角蛤) Angulus vestalis (Hanley, 1844) [a, e, h57]

339. 拟衣角樱蛤 Hanleyanus vestalioides Yokoyama 1920 [d, h57]

340. 彩虹明樱蛤 Iridona iridescens (Benson, 1842) [d, e]

341. 菲律宾明樱蛤 Jitlada philippinarum (Hanley, 1844) [e]

342. 沟纹智免蛤 (沟纹巧樱蛤) Leporimetis coarctata (Philippi, 1845) [h57]

343. 布氏马加蛤(布氏马甲蛤) Macalia bruguieri (Hanley, 1844) [a, h57]

344. 美女白樱蛤 Macoma candida (Lamarck, 1878) [a, e, f, g]

345. 江户明樱蛤 Moerella jedoensis (Lischke, 1872) [e, h57]

346. 亮樱蛤 Nitidotellina hokkaidoensis (Habe, 1961) [h57]

347. 小亮樱蛤 Nitidotellina lischkei M. Huber, Langleit et Kreipl, 2015 [e, p]

348. 前裂白樱蛤 (截形白樱蛤) Psammacoma gubernaculum (Hanley, 1844) [e]

349. 闪光桔蛤(忱蛤) Pulvinus micans (Hanley, 1844) [p]

350. 透明美丽蛤(拟箱美丽蛤) Serratina diaphana (Deshayes, 1855) [b, d, h57]

351. 仿樱蛤(帝汶樱蛤) Tellinides timorensis Lamarck, 1818 [h57]

352. 蜊樱蛤 Tellinimactra edentula (Spengler, 1798) [a, h57]

船蛆科 Teredinidae

353. 船蛆 Teredo navalis Linnaeus, $1758[\mathrm{~b}, \mathrm{~d}, \mathrm{k}, \mathrm{x}]$

色雷西蛤科 Thraciidae

354. 金星蝶铰蛤 Trigonothracia jinxingae F.-S. Xu, 1980 [e] 棱蛤科 Trapezidae

355. 纹斑棱蛤 Neotrapezium liratum (Reeve, 1843) [b, d]

356. 次光滑棱蛤(亚光棱蛤) Neotrapezium sublaevigatum (Lamarck, 1819) [i]

蹄蛤科 Ungulinidae

357. 托氏圆蛤(津知圆蛤) Cycladicama tsuchii Yamamoto et Habe, 1961 [p] 


\section{窝蛤科 Veneridae}

358. 对角蛤 Antigona lamellaris Schumacher, 1817 [a]

359. 中国仙女蛤 Callista chinensis (Holten, 1802) [a, b, d, h24, i, k]

360. 棕带仙女蛤 Callista erycina (Linnaeus, 1758) [b]

361. 美女蛤(面具美女蛤) Circe scripta (Linnaeus, 1758) [b, d, f, h24]

362. 美叶雪蛤 Clausinella calophylla (Philippi, 1836) [a, b, d, h24, i, k]

363. 头巾雪蛤 Clausinella tiara (Dillwyn, 1817) [a, b, d, f, h24, i, k]

364. 突畸心蛤 Cryptonema producta (Kuroda et Habe, 1951) [b, d, f, h24, k]

365. 青蛤 Cyclina sinensis (Gmelin, 1791) [b, d, e, h24, k, x]

366. 巧环楔形蛤 Cyclosunetta concinna (Dunker, 1858) [a, b, d, f, h24, k]

367. 饼干镜蛤 Dosinia biscocta (Reeve, 1850) [a]

368. 薄片镜蛤 Dosinia corrugata (Reeve, 1850) [b, d, g, h24, k]

369. 突角镜蛤 Dosinia cumingii (Reeve, 1850) [d, f]

370. 帆镜蛤 Dosinia histrio (Gmelin, 1791) [e]

371. 日本镜蛤 Dosinia japonica (Reeve, 1850) [b, d, h24, k, x]

372. 歧脊加夫蛤 Gafrarium divaricatum (Gmelin, 1791) [a, b, d, h24, k]

373. 等边浅蛤(黑浅蛤) Gomphina aequilatera (G.B. Sowerby I, 1825) [a, b, d, h24, k, x]

374. 越鳞蛤 Irus mitis (Deshayes, 1854) [b, d, h24]

375. 裂纹格特蛤(环沟格特蛤) Marcia hiantina (Lamarck, 1818) [d]

376. 日本格特蛤(日本女神蛤) Marcia japonica (Gmelin, 1791) [a]

377. 斧文蛤 Meretrix lamarckii Deshayes, 1853 [a]

378. 文蛤 Meretrix meretrix (Linnaeus, 1758) [a, b, d, e, k]

379. 短文蛤 Meretrix petechailis (Lamarck, 1810) [a]

380. 和蔼巴非蛤 Paphia amabilis (Philippi, 1847) [b, d, f, i, k]

381. 真曲巴非蛤 Paphia euglypta (Philippi, 1847) [b, d, f, h24, i, j, k]

382. 锯齿巴非蛤(屈巴非蛤) Paphia gallus (Gmelin, 1791) [a, b, d, f, h24, k]

383. 纹斑巴非蛤 Paphia lirata (Philippi, 1848) [b, d, h24, i, j, k]

384. 掅巴非蛤 Paphia schnelliana (Dunker, 1865) [a, h24]

385. 半皱纹巴非蛤 Paphia semirugata (Philippi, 1847) [a]

386. 波纹巴非蛤 Paphia undulata (Born, 1778) [a, b, d, g, h24, i, k]

387. 凸镜蛤 Pelecyora nana (Reeve, 1850) [e]

388. 三角凸卵蛤 Pelecyora trigona (Reeve, 1850) [b, d]

389. 曲波皱纹蛤 Periglypta chemnitzi (Hanley, 1844) [a, b, d, f, h24, j, k]

390. 皱纹蛤 Periglypta puerpera (Linnaeus, 1771) [a]

391. 绿雪蛤 Placamen chloroticum (Philippi, 1849) [i]

392. 伊萨伯雪蛤 Placamen isabellina (Philippi, 1849) [a, b, d, h24, k]

393. 菲律宾蛤仔 Ruditapes philippinarum (A. Adams et Reeve, 1850) [a, b, d, e, h24, k]

394. 小楔形蛤 Sunetta solanderii (Menke, 1843) [a]

395. 杂色蛤仔 Venerupis aspera (Quoy et Gaimard, 1835) [a, b, d, e, h24, i, j, k, x] 


\section{参考文献}

Cai YY (1966) A preliminary investigation on the Cladocera shells in the coast of Fujian. Chinese Journal of Zoology, 8(2), 76-80. (in Chinese) [蔡英亚 (1966) 福建沿海瓣鳃纲贝类的初步调查. 动物学杂志, 8(2), 76-80.]

Cai YY, Lin YM, Ou RM (1990) Study on the molluscan fauna of Nanao Islands, South China Sea. Journal of Zhanjiang Fisheries College, 10(1), 1-13. (in Chinese with English abstract) [蔡英亚, 林永木, 欧瑞木 (1990) 广东南澳岛贝类区系的研究. 湛江 水产学院学报, 10(1), 1-13.]

Chen ZY (2012) Study on the Taxonomy of Pyramidellidae of China Seas. PhD dissertation, Institute of Oceanology, Chinese Academy of Sciences, Qingdao, Shandong. (in Chinese with English abstract) [陈志云 (2012) 中国海小塔螺科Pyramidellidae系统分类学 研究. 博士学位论文, 中国科学院海洋研究所, 山东青岛.]

Dong ZZ (2002) Fauna Sinica, Invertebrata, Vol. 29. Science Press, Beijing. (in Chinese) [董正之 (2002) 中国动物志·无脊椎动物, 第二十九卷. 科学出版社, 北京.]

Editorial Committee of China's Bays (1994) China’s Bays, Vol. 7. Bays of Northern Fujian. China Ocean Press, Beijing. (in Chinese) [中国海湾志编纂委员会 (1994) 中国海湾志, 第7分册 (福建省北部海湾). 海洋出版社, 北京.]

Editorial Committee of Fujian Provincial Records (2003) Fujian Provincial Records: Biota. China Local Records Publishing House, Beijing. (in Chinese) [福建省地方志编纂委员会 (2003) 福建省志: 生物志. 方志出版社, 北京.]

Huang YQ, Li RG, Jiang JX (2009) Biodiversity and distribution of mollusc around the waters of islands, Fujian Province. Marine Sciences, 33(10), 77-83. (in Chinese with English abstract) [黄雅琴, 李荣冠, 江锦祥 (2009) 福建海岛水域软体动物多样性与 分布. 海洋科学, 33(10), 77-83.]

Huang ZG, Lin M (2012) The Living Species in China’s Seas, Vol. 1. China Ocean Press, Beijing. (in Chinese) [黄宗国，林茂 (2012) 中国海洋物种多样性(上册). 海洋出版社, 北京.]

Li BQ (2007) Taxonomic and Faunal Study of Turridae (Gastropoda: Neogastropoda) of the China Seas. PhD dissertation, Institute of Oceanology, Chinese Academy of Sciences, Qingdao, Shandong. (in Chinese with English abstract) [李宝泉 (2007) 中国海塔螺 科系统分类学和动物地理学研究. 博士学位论文, 中国科学院海洋研究所, 山东青岛.]

Li FL, Lin MY (1999) Studies on Chinese species of the family Terebridae. Studia Marina Sinica, 41, 190-220. (in Chinese with English abstract) [李凤兰, 林民玉 (1999) 中国近海笋螺科的研究. 海洋科学集刊, 41, 190-220.]

Li RG (2010) Macrobenthos in Fujian Coastal Zone and Western Taiwan Strait. China Ocean Press, Beijing. (in Chinese) [李荣冠 (2010) 福建海岸带与台湾海峡西部海域大型底栖生物. 海洋出版社，北京.]

Tchang S, Tsi CY (1962) Economic Fauna of China: Marine Molluscs. Science Press, Beijing. (in Chinese) [张胥, 齐钟彦 (1962) 中 国经济动物志: 海产软体动物. 科学出版社, 北京.]

Wang FP, Huang YM (1993) Studies on the Prosobranchia fauna of Fujian coast. Journal of Fujian Normal University (Natural Science), 9(4), 85-95. (in Chinese with English abstract) [王方平, 黄一鸣 (1993) 福建沿海前鳃类区系的研究. 福建师范大学 学报(自然科学版), 9(4), 85-95.]

Wang FP, Huang YM (1994) Studies on the bivalvia fauna from the Fujian coast. Journal of Fujian Normal University (Natural Science), 10(3), 81-91. (in Chinese with English abstract) [王方平, 黄一鸣 (1994) 福建沿海双壳类区系的研究. 福建师范大 学学报(自然科学版), 10(3), 81-91.]

Wang ZR (1985) Studies on Chinese species of the family Pectinidae. VII. Chlamydinae (Genus Semipallium). Oceanologia et Limnologia Sinica, 16, 502-506. (in Chinese with English abstract) [王祯瑞 (1985) 中国近海扇贝科的研究. VII. 栉孔扇贝亚 科(拟套扇贝属). 海洋与湖沼, 16, 502-506.]

Wang ZR (1997) Fauna Sinica, Mollusca, Bivalvia, Mytiloida. Science Press, Beijing. (in Chinese) [王祯瑞 (1997) 中国动物志·软 体动物门·双壳纲·贻贝目. 科学出版社, 北京.]

Xu FS (1997) Bivalve Molluscs of China Sea. Science Press, Beijing. (in Chinese) [徐凤山 (1997) 中国海双壳类软体动物. 科学 出版社, 北京.]

Xu FS (2012) Fauna Sinica, Invertebrata, Vol. 48. Science Press, Beijing. (in Chinese) [徐凤山 (2012) 中国动物志·无脊椎动物, 第 四十八卷. 科学出版社, 北京.]

Xu FS, Zhang JL (2018) Fauna Sinica, Invertebrata, Vol. 57. Science Press, Beijing. (in Chinese) [徐凤山, 张均龙 (2018) 中国动 物志·无脊椎动物, 第五十七卷. 科学出版社, 北京.]

Zhang SP (2007) On nine new record species of Ergalataxinae (Gastropoda, Muricidae) from China coast. Oceanologia et Limnologia Sinica, 38, 542-548. (in Chinese with English abstract) [张素萍 (2007) 中国近海爱尔螺亚科九新记录(腹足纲: 骨螺科). 海洋 与湖沼, 38, 542-548.]

Zhang SP (2010) Comparative study on two confused species of Nassarius. Acta Zootaxonomica Sinica, 35, 868-870. (in Chinese with English abstract) [张素萍 (2010) 织纹螺属两个混淆种的比较研究. 动物分类学报, 35, 868-870.]

Zhang SP (2016) Fauna Sinica, Invertebrata, Vol. 56. Science Press, Beijing. (in Chinese) [张素萍 (2016) 中国动物志·无脊椎动物, 第五十六卷. 科学出版社, 北京.]

Zhang SP, Ma XT (2004) Fauna Sinica, Invertebrata, Vol. 34. Science Press, Beijing. (in Chinese) [张素萍, 马绣同 (2004) 中国动 物志·无脊椎动物, 第三十四卷. 科学出版社, 北京.] 
Zhang SP, Wei P (2011) Cowries and Their Relatives of China. China Ocean Press, Beijing. (in Chinese) [张素萍, 尉鹏 (2011) 中 国宝贝总科图鉴. 海洋出版社，北京.]

Zhang SQ (2015) Study on the Taxonomy and Zoogeography of the Buccinidae of China Seas. PhD dissertation, Institute of Oceanology, Chinese Academy of Sciences, Qingdao, Shandong. (in Chinese with English abstract) [张树乾 (2015) 中国海蛾螺 科Buccinidae系统分类学与动物地理学研究. 博士学位论文, 中国科学院海洋研究所, 山东青岛.]

Zhang SQ, Zhang SP (2020) Taxonomic study of Lottioidea from the coast of China based on shell and radular morphology. Marine Sciences, 44(5), 87-95. (in Chinese with English abstract) [张树乾，张素萍 (2020) 基于贝壳和齿舌对中国近海笠贝总科动物 的分类学研究. 海洋科学, 44(5), 87-95.]

Zhong YP, Yang RQ (1996) The new record of Prosobranchia along the Coast of Fujian. Journal of Xiamen Fisheries College, 18(1), 50-54. (in Chinese with English abstract) [钟幼平, 杨瑞琼 (1996) 福建沿海前鳃类软体动物种类新记录. 厦门水产学院学报, $18(1), 50-54$.

Zhuang QQ (2001) Fauna Sinica, Mollusca, Bivalvia, Veneridae. Science Press, Beijing. (in Chinese) [庄启谦 (2001) 中国动物志·软 体动物门·双壳纲·窝蛤科. 科学出版社, 北京.] 